University of Nebraska - Lincoln

DigitalCommons@University of Nebraska - Lincoln

Publications, Agencies and Staff of the U.S.

Department of Commerce

U.S. Department of Commerce

2011

\title{
A MODEL OF CHINOOK SALMON POPULATION DYNAMICS INCORPORATING SIZE-SELECTIVE EXPLOITATION AND INHERITANCE OF POLYGENIC CORRELATED TRAITS
}

Jeffrey F. Bromaghin

U.S. Fish and Wildlife Service, jeffrey_bromaghin@fws.gov

Ryan M. Nielson

Western EcoSystems Technology, Inc., rnielson@west-inc.com

Jeffrey J. Hard

National Marine Fisheries Service, jeff.hard@noaa.gov

Follow this and additional works at: https://digitalcommons.unl.edu/usdeptcommercepub

Part of the Environmental Sciences Commons

Bromaghin, Jeffrey F.; Nielson, Ryan M.; and Hard, Jeffrey J., "A MODEL OF CHINOOK SALMON POPULATION DYNAMICS INCORPORATING SIZE-SELECTIVE EXPLOITATION AND INHERITANCE OF POLYGENIC CORRELATED TRAITS" (2011). Publications, Agencies and Staff of the U.S. Department of Commerce. 244.

https://digitalcommons.unl.edu/usdeptcommercepub/244

This Article is brought to you for free and open access by the U.S. Department of Commerce at DigitalCommons@University of Nebraska - Lincoln. It has been accepted for inclusion in Publications, Agencies and Staff of the U.S. Department of Commerce by an authorized administrator of DigitalCommons@University of Nebraska - Lincoln. 


\title{
A MODEL OF CHINOOK SALMON POPULATION DYNAMICS INCORPORATING SIZE-SELECTIVE EXPLOITATION AND INHERITANCE OF POLYGENIC CORRELATED TRAITS
}

\author{
JEFFREY F. BROMAGHIN* \\ U.S. Fish and Wildlife Service, Fisheries and Ecological Services, 1011 East Tudor \\ Road, Anchorage, AK 99503 \\ E-mail: jeffrey_bromaghin@fws.gov \\ RYAN M. NIELSON \\ Western EcoSystems Technology, Inc., 200 South Second Street, Suite B, \\ Laramie, WY 82070 \\ E-mail: rnielson@west-inc.com \\ JEFFREY J. HARD \\ National Marine Fisheries Service, Northwest Fisheries Science Center, \\ Conservation Biology Division, 2725 Montlake Blvd. East, Seattle, WA 98112-2097 \\ E-mail: jeff.hard@noaa.gov
}

\begin{abstract}
Concern regarding the potential for selective fisheries to degrade desirable characteristics of exploited fish populations is growing worldwide. Although the occurrence of fishery-induced evolution in a wild population has not been irrefutably documented, considerable theoretical and empirical evidence for that possibility exists. Environmental conditions influence survival and growth in many species and may mask comparatively subtle trends induced by selective exploitation, especially given the evolutionarily short time series of data available from many fisheries. Modeling may be the most efficient investigative tool under such conditions. Motivated by public concern that large-mesh gillnet fisheries may be altering Chinook salmon in western Alaska, we constructed a stochastic model of the population dynamics of Chinook salmon. The model contained several individually based components and incorporated size-selective exploitation, assortative mating, size-dependent female fecundity, density-dependent survival, and the heritability of size and age. Substantial reductions in mean size and age were observed under all scenarios. Concurrently reducing directional selection and increasing spawning abundance was most effective in stimulating population
\end{abstract}

\footnotetext{
${ }^{*}$ Corresponding author. J. F. Bromaghin, U.S. Geological Survey, Alaska Science Center, 4210 University Drive, Anchorage, Alaska 99508; e-mail: jbromaghin@usgs.gov.

Received by the editors on $20^{\text {th }}$ August, 2009. Accepted $1^{\text {st }}$ August, 2010.
} 
recovery. Use of this model has potential to improve our ability to investigate the consequences of selective exploitation and aid development of improved management strategies to more effectively sustain fish and fisheries into the future.

KEY WORDS: Fishery-induced evolution, fishery-induced adaptation, selective fisheries, Oncorhynchus tshawytscha, fishery management, fishery conservation, individual-based model, age-structured model, Yukon River.

1. Introduction. There is growing global concern that fishery management practices are leading to undesirable shifts in the life history and demographic composition of exploited populations, reduced genetic variation and spatial diversity, and fishery collapse and ecosystem restructuring (e.g., Levin et al. [2006], Walsh et al. [2006], Andersen et al. [2007], Kuparinen and Merilä [2007], Law [2007], Swain et al. [2007], Allendorf et al. [2008], Fenberg and Roy [2008], Ainley and Blight [2009]). Excessive exploitation rates and selection for large individuals have often been implicated as precursors of such population responses (e.g., Law [2000], Jørgensen et al. [2007], Safina and Klinger [2008]). Fisheries are often managed to produce maximum sustained yield (MSY; Ricker [1958, 1969], Walters and Martell [2004]), even though management for MSY has frequently been criticized (e.g., Larkin [1977]). For many populations, management objectives such as MSY are realized at a high exploitation rate. The Food and Agriculture Organization of the United Nations recently estimated that approximately $50 \%$ of the world's primary fish stocks are fully exploited and producing close to their maximum yields, while another $25 \%$ are in various states of overexploitation (FAO [2004]). If fish populations respond to high, selective exploitation by evolving life history strategies that lower abundance and reduce productivity, grave consequences for fish, fisheries, and aquatic ecosystems may be occurring on a global scale (Heino [1998], Law [2000], Conover and Munch [2002]).

Although Hard et al. [2008] concluded that no single study has irrefutably demonstrated fishery-induced evolution in a wild population, considerable theoretical and empirical evidence for its occurrence exists (e.g., Ricker [1981, 1995], Heino [1998], Law [2000], Carlson et al. [2007]). Modeling investigations tend to conclude that size- or ageselective fisheries can be a powerful force in modifying population 
structure (e.g., Kaitala and Getz [1995], Martínez-Garmendia [1998], Ratner and Lande [2001], Brown et al. [2008]). Conover and Munch [2002] conducted experiments in which large and selective harvests of Atlantic silverside (Menidia menidia) led to substantial changes in fish size in as few as three generations. In addition, empirical evidence that evolutionary changes in the life histories of some heavily exploited fish populations may already be widespread is accumulating (e.g., Ricker [1981], Law [2000], Edeline et al. [2007], ICES [2007], Kuparinen and Merilä [2007], Swain et al. [2007]). Conversely, in a meta-analysis of marine fisheries studies, Hilborn and Minte-Vera [2008] concluded that the evidence for fishery-induced evolution of growth rates was weak. One implication of this finding is that fishery-induced evolution in size and age at maturation of wild populations may occur slowly and be difficult to detect (Law [2007]).

Investigations of demographic trends in wild fish populations have necessarily been based on observational data and therefore have not been able to ascertain cause. For example, none of the investigations involving salmon has been able to exclude the possibility that other factors, such as density-dependent growth or environmental conditions, underlie observed trends in size or age (Hard et al. [2008]). Even so, fishery-induced evolution cannot be excluded as a potential contributor to demographic and life history trends in many populations. The relative importance of multiple potential factors underlying trends in any single population will be difficult to determine with observational data, though the conceptual importance of population genetics is obvious. The genetic composition of unfished populations is the net result of counterbalancing evolutionary forces (Naish and Hard [2008]). High and selective exploitation has the potential to substantially decrease genetic diversity (Allendorf et al. [2008]) and reduce the capacity of a population to respond to natural evolutionary forces, even if exploitation and the intensity of selection are subsequently reduced (Hutchings and Rowe [2008], Allendorf and Hard [2009], Conover et al. [2009]). Indeed, the failure of collapsed populations to recover following substantial reductions in exploitation provided early indications that fishery-induced evolution might result from overexploitation (e.g., Hutchings [2000]). Law [2000] listed numerous examples of changing populations of various species, including Pacific salmon (Oncorhynchus spp.), and concluded, as did Jørgensen et al. [2007], that the primary 
question is not whether fishery-induced evolution is occurring but rather how quickly.

Implicating a single cause for change in a population characteristic as complex as life-history strategy is exceedingly difficult (Fenberg and Roy [2008]), particularly with observational data. A variety of environmental factors can produce changes in salmon characteristics, some of which might mistakenly be attributed to fishing (e.g., Fukuwaka and Morita [2008]). With respect to Pacific salmon, investigations variously attribute trends in population traits to selective fisheries, climatic or oceanic conditions, and density-dependent effects. In an early paper, Vaughan [1947] speculated that fishing could have led to delayed runtiming in southeastern Alaskan pink salmon (O. gorbuscha) during the early $20^{\text {th }}$ century. Hankin and Healey [1986] concluded that selective fisheries can decrease the mean age of Chinook salmon (O. tshawytscha) populations and increase the probability of significant population decline. Hamon et al. [2000] concluded that selectivity in gillnet fisheries can be a strong selective force on the morphology (body shape as well as size) of sockeye salmon (O. nerka). Kendall et al. [2009] estimated standardized selection differentials for a 60-year dataset of adult Bristol Bay sockeye salmon and found that selection intensity often differed substantially between sexes and among years. Although Bigler et al. [1996] documented a decline in the size of Pacific salmon, the cause was primarily attributed to ocean conditions and density-dependent effects on growth. Healey [1986] similarly concluded that observed declines in the size of Pacific salmon previously attributed to selective fisheries were at least partially due to environmental conditions and, like Riddell [1986], noted that fishery mortality accounts for only a fraction of total mortality. However, Quinn et al. [2002] found that fishery selectivity was stronger than opposing selective pressures in determining the timing of Chinook and coho (O. kisutch) salmon spawning. Fukuwaka and Morita [2008] documented an increase in the maturation size of chum salmon $(O$. keta) following cessation of high seas gillnet fisheries, although temporally correlated environmental conditions could not be ruled out as causal factors. Although investigations have been inconclusive with respect to cause, the heritability of numerous traits has been established for several fish species, including salmon, (e.g., Hankin et al. [1993], Hard [1995, 2004], Carlson and Seamons [2008], 
Hard et al. [2008]), which directly implies that population structure has genetic underpinnings and could respond to selection.

Chinook salmon in Western and Interior Alaska, USA, are predominantly harvested in gillnet fisheries, many of which utilize large-mesh nets. For example, Yukon River Chinook salmon have been fished commercially for a century, and sizeable catches are taken in subsistence (United States) and aboriginal (Canada) fisheries (Buklis [1999], JTC [2006]). Recent declines in productivity and perceived reductions in size and age at maturation have generated speculation among fishers, fishery biologists, and regulatory boards regarding potential fisheryinduced evolution. Analyses of existing data have been inconclusive, although suggestive, with respect to trending population demographics (Bigler et al. [1996], Hyer and Schleusner [2005]). In addition to various data limitations underlying each analysis, high levels of variation over evolutionarily short time scales for which data are available might be expected to mask any genetically based trends that may exist.

Large-mesh gillnet fisheries undoubtedly have the potential to alter characteristics of Chinook salmon populations. However, the population dynamics and life-history strategies of Chinook salmon are complex, and adaptive mechanisms to moderate fishery-induced evolutionary pressures almost certainly exist. Hard [2004] concluded that the "intensity of stabilizing natural selection on size is critically important in determining response to fishing selection." Given this complexity, it is difficult to confidently predict the long-term effects of size-selective fisheries on Chinook salmon. Nevertheless, an improved understanding of how opposing selective pressures might interact to control population dynamics would be beneficial, both for inferring historic population characteristics and trends and for developing informed management strategies to maintain desirable population characteristics into the future.

For these reasons, we used computer simulation to investigate the potential evolutionary consequences of size-selective fishing for largebodied, late-maturing Chinook salmon, such as those found in Western Alaska. We constructed a stochastic, individual-based model integrating population dynamics and the inheritance of correlated traits. Our primary objective was to investigate the potential for long-term, selective exploitation to induce trends in population demographics and productivity. If a population-level response seemed likely, we also wanted 


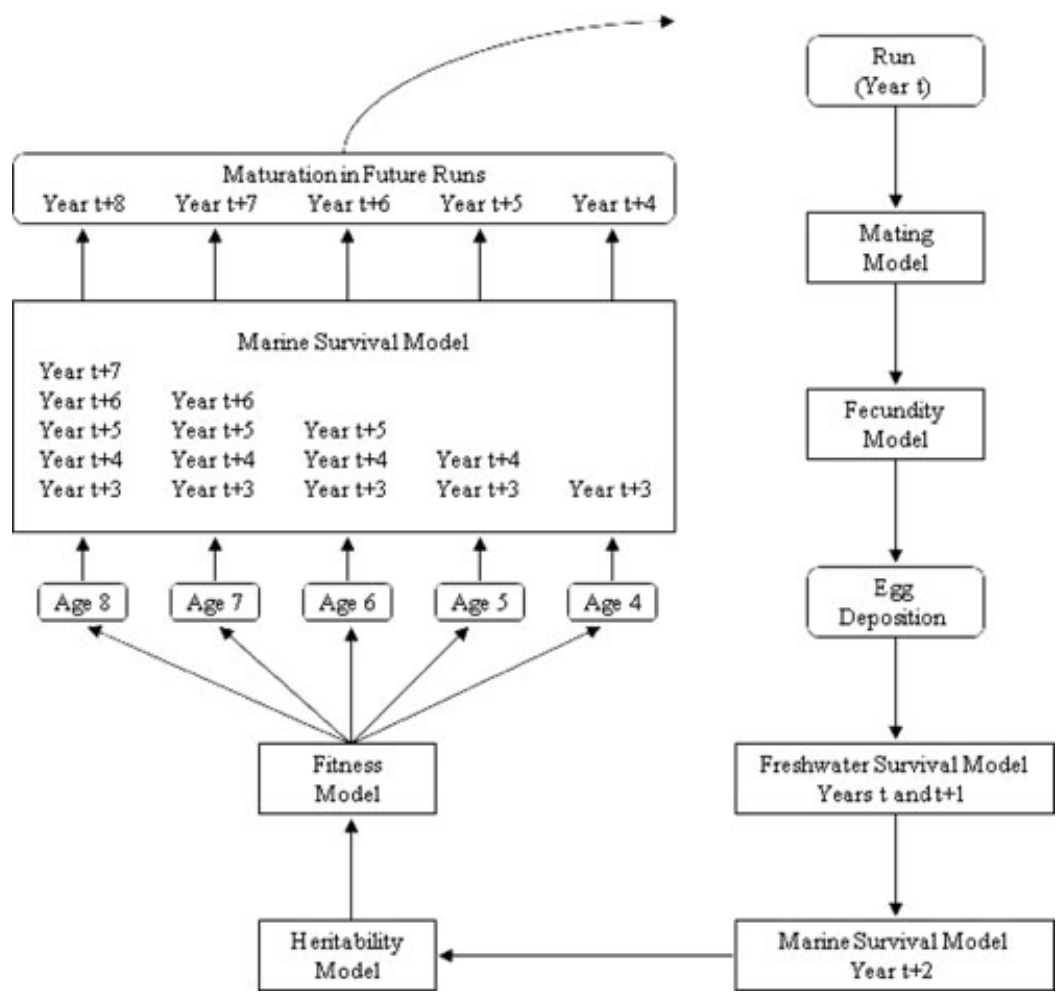

FIGURE 1. A schematic diagram of the primary components of the Chinook salmon population dynamics model. Rectangles with squared corners represent model components, while rectangles with rounded corners represent submodel results.

to identify management strategies most likely to induce adaptation and develop recommendations for alternative strategies to minimize the potential impacts of fishery-induced evolution.

2. Model development. We approached model development by conceptualizing population dynamics as the net result of a series of sequential stages within the life history of Chinook salmon (Figure 1). A submodel for each stage was developed and parameterized using the best available information, which included literature, agency reports, 
available data or analyses, and professional judgment. The majority of the simulation code was written in $R$, version 2.60 (RDCT [2007]). However, to increase execution speed, the mating submodel (see Section 2.2) was written in FORTRAN 95 (Metcalf et al. [2004]) and compiled using the freeware G95 compiler (http://www.g95.org/ index.shtml).

2.1. Age, sex, and length submodel. Pacific salmon are semelparous; sexually mature individuals migrate from the ocean to their natal freshwater streams, reproduce (spawn), and die. Chinook salmon are commonly divided into two races, or life-history classifications (Quinn [2005]). Ocean-type Chinook salmon juveniles, which are more common in the southern portion of their range, migrate to the ocean shortly after emergence from streambed gravels. Juveniles of the stream-type race generally spend one full year in freshwater before smolting, although a small proportion of juveniles from some populations may reside in freshwater for 2 years. Western Alaska Chinook salmon are of the stream-type variety, and nearly all spend 1 year in freshwater. The total age of mature individuals ranges from 3 to 8 , but the youngest and oldest age classes are currently rare in western Alaska. The youngest fish are predominantly male, while a majority of the oldest age classes are female (Bales 2008).

The demographic composition (sex, age, and length) of a spawning migration of Chinook salmon was parameterized using a variety of Yukon River data sources. All data sources are biased to an unknown extent, either by gear selectivity or the selective removal of a portion of the migrating adults in downriver fisheries, so each data source was used in ways to exploit its strengths and minimize the influence of suspected bias.

The target average age composition of a spawning migration was based on a combination of three analyses of productivity available for Yukon River Chinook salmon populations: the Canadian main stem population for parent years 1979-1997 (JTC [2008]), the Chena River population for parent years 1986-1994 (Evenson [2002]), and the Salcha River population for parent years 1987-1994 (Evenson [2002]). For each year, the estimated numbers of mature fish returning at age were summed across the analyses and the proportions by age were computed from the sums, after discarding the small number of age-3 fish (annual 
TABLE 1. Average age composition of spawning migrations.

\begin{tabular}{lccccc} 
& \multicolumn{5}{c}{ Age } \\
\cline { 2 - 6 } Composition & 4 & 5 & 6 & 7 & 8 \\
\hline Empirical average & 0.057 & 0.260 & 0.557 & 0.121 & 0.003 \\
Simulation target average & 0.030 & 0.240 & 0.560 & 0.140 & 0.030 \\
\hline
\end{tabular}

average contribution of $0.2 \%$ ) to speed execution and reduce memory requirements. The proportions by age were then averaged across years and shifted slightly toward older-aged fish under the presumption that older fish may have been more prevalent in prior decades (Table 1). Although we have no data on the demographic composition of historic runs, we suspect that aboriginal harvests were less selective for large fish than modern fisheries and that older, larger fish were more prevalent in prior decades, which is consistent with the testimony of many local elders. In addition, this allowed us to initiate simulations with a greater number of the oldest and largest fish in the unfished population (Table 1).

Sex composition for each age was modeled using a combination of two data sources. The first source consisted of records obtained from 1960 to 2005 during commercial fishery sampling in the lower-river fishing district $\mathrm{Y} 1$ by the Alaska Department of Fish and Game (ADF\&G). These data were sampled from fish caught using gillnets of various mesh sizes, although a majority of individuals were undoubtedly caught in largemesh gear. The second data set consisted of lower-river test-fishery samples obtained from 1998 to 2005 (both data sets provided courtesy of Danielle Evenson, ADF\&G, Anchorage, AK). These two data sets were combined, and all records with missing sex, age, or length data were discarded. Records of fish with length $<300 \mathrm{~mm}$ (presumed to be data recording errors), total age of 3 (very rare), and fish of freshwater age 2 (also rare) were also discarded. The mean and variance of length were then computed for each combination of sex and age. All records with length greater than 3.5 standard deviations from their mean were identified as potentially erroneous outliers and discarded. The proportion of the individuals of each age that were females was computed 
TABLE 2. Proportion female by age.

Age

\begin{tabular}{lcccc}
\hline 4 & 5 & 6 & 7 & 8 \\
\hline 0.05 & 0.29 & 0.61 & 0.63 & 0.67 \\
\hline
\end{tabular}

TABLE 3. Age composition, and the mean and standard deviation of age, by sex.

Age

\begin{tabular}{lccccccc}
\cline { 2 - 5 } Sex & 4 & 5 & 6 & 7 & 8 & Mean & Standard deviation \\
\hline Female & 0.003 & 0.134 & 0.656 & 0.169 & 0.039 & 6.1 & 0.68 \\
Male & 0.059 & 0.356 & 0.456 & 0.108 & 0.021 & 5.7 & 0.82 \\
\hline
\end{tabular}

using the resulting data set of 64,634 records (Table 2). This data set is a complicated compilation of records obtained at various times using a diversity of mesh sizes. Although the data are undoubtedly biased by gear selectivity for length, conditioning on age before computing the proportion female was expected to reduce bias, and the resulting estimates of sex composition should provide reasonable approximations. This data set was also used to estimate the correlation between age and length: 0.82 and 0.58 for males and females, respectively.

The target average age composition (Table 1) and proportion female given age (Table 2) were multiplied and then scaled to sum to 1.0 for each sex to provide a model for average age composition by sex (Table 3).

The mean and standard deviation of length (measured from mid-eye to fork-of-tail), by sex, was estimated using data collected from 1995 to 2004 for species apportionment of sonar-derived estimates of total fish abundance near Pilot Station, Alaska (Carroll and McIntosh [2008]; data provided courtesy of Toshihide Hamazaki, ADF\&G, Anchorage, AK). These fish were caught in gillnets of various mesh sizes, from 2.75 
to 8.5 in. stretch mesh, and may therefore be less biased than other data sources, although a proportion of the commercial and human-food catch is taken downriver from this location. However, reduced catches were taken in most of these years due to below-average run sizes, so the bias induced by fishery removals was not thought to be substantial. In addition, the sex of most fish was conclusively established by visual inspection of reproductive tissues rather than the more common assessment of external secondary sex characteristics. The net selectivity estimates of Bromaghin [2005] (see Section 2.6) were used to derive a weighting factor for each fish, based on its length and the mesh in which it was caught; the weighting factor was taken as the inverse of the relative selectivity of each fish. The resulting weighted means and standard deviations of length were 808 and $91 \mathrm{~mm}$ for females and 720 and $132 \mathrm{~mm}$ for males.

Given the parameterization discussed earlier, the joint distribution of age and length was modeled using a bivariate normal probability density function (Kotz et al. [2000]) for each sex. Although age is a discrete characteristic, considering age as a continuous variable with several categories - a threshold trait - produces no serious problems for analysis or interpretation (Falconer and McKay [1996]). Cut-points were established for each discrete age, and a continuous value falling within the interval bounded by two cut-points was converted to the discrete age associated with that interval. Cut-points were established separately for each sex so that the resulting proportions by age equaled the proportions given in Table 3.

The means, standard deviations, and the correlations between age and length, as well as the cut-points, described above were used as initial parameter values in the bivariate normal model. During model calibration (see Section 2.7), there was a tendency for mean lengths and ages to drift upward in the first few years and stabilize at means above the target values. To counteract this drift, the initial parameter values were adjusted to produce a stable model with the desired age, sex, and size composition (Tables 1-3); the final values of these parameters are presented in Table 4.

We attempted to use available data on age, sex, and length in ways to mimic the demographic composition of Yukon River Chinook salmon as closely as possible while minimizing the effects of any biases they might contain. However, the degree to which we were successful is unknown, 
TABLE 4. Parameter values related to age and length computed from empirical data (before calibration) that were modified during model calibration (after calibration) and used to initiate the simulation, by sex.

\begin{tabular}{|c|c|c|c|c|}
\hline \multirow[b]{2}{*}{ Parameter } & \multicolumn{2}{|c|}{$\begin{array}{c}\text { Before } \\
\text { calibration }\end{array}$} & \multicolumn{2}{|c|}{ After calibration } \\
\hline & Male & Female & Male & Female \\
\hline Mean length & 720 & 808 & 680 & 790 \\
\hline Standard deviation length & 132 & 91 & 143 & 99 \\
\hline Mean age & 5.7 & 6.1 & 5.6 & 6.0 \\
\hline Standard deviation age & 0.820 & 0.680 & 0.902 & 0.715 \\
\hline Cut-point between age 4 and 5 & 4.4216 & 4.3050 & 4.32263 & 4.31170 \\
\hline Cut-point between age 5 and 6 & 5.5244 & 5.3874 & 5.44756 & 5.39983 \\
\hline Cut-point between age 6 and 7 & 6.6282 & 6.6290 & 6.58131 & 6.64326 \\
\hline Cut-point between age 7 and 8 & 7.3729 & 7.2488 & 7.31360 & 7.25576 \\
\hline
\end{tabular}

and the resulting age and size distributions are best viewed as representing a generic large-bodied, late-maturing, stream-type Chinook salmon population.

2.2. Mating submodel. Males and females were paired for reproduction using a two-stage mating model. The first stage, which we term "Proposal," was based on observations of the attractiveness of females to males (figure 4 of Foote [1988]). We used a quadratic logistic function to model the probability that a male proposes to a female,

$$
P(\text { Proposal })=a+(b-a)\left\{1+\mathrm{e}^{-\beta_{0}-\beta_{1} x-\beta_{2} x^{2}}\right\}^{-1},
$$

where $a=0.05, b=0.95, \beta_{0}=-10, \beta_{1}=10, \beta_{2}=3$, and $x$ is the ratio of female to male length (Figure 2).

We evaluated a number of functions for the probability a female accepts a male proposal (termed "Acceptance"). We were unable to find support for any particular function or form in the literature, and 


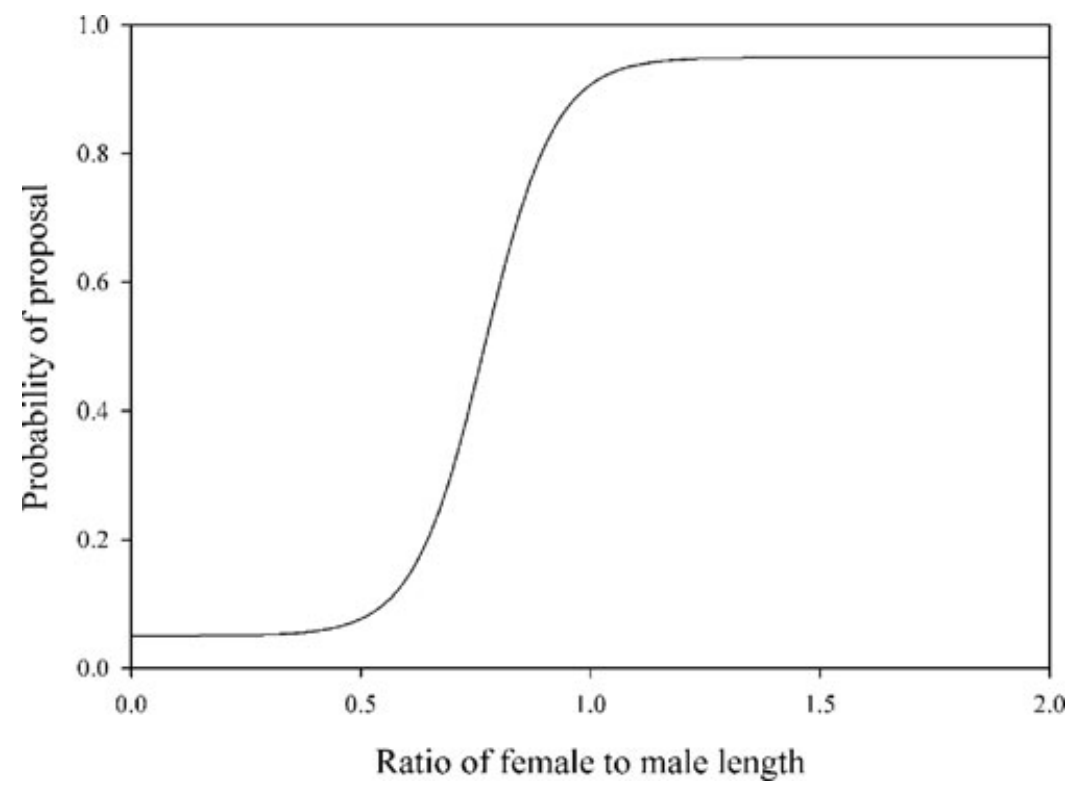

FIGURE 2. Probability a male proposes to a female as a function of the ratio of female to male length. The same function, with the horizontal axis redefined as the ratio of male to female length, was used for the probability a females accepts a male proposal.

eventually selected (1) to also represent the probability of acceptance given proposal, with the same parameter values but $x$ redefined as the ratio of male to female length. Both males and females therefore had a preference for mates that were as large or larger than themselves, with a modest positive correlation between mate sizes (Kaitala and Getz [1995]).

This submodel was implemented sequentially for each female in the reproducing population. For a given female, a male was selected at random from among all available males. The probability the two would mate was determined stochastically using the product of the probabilities of Proposal and Acceptance. If the pair did not mate, an additional male was selected at random and the stochastic process was repeated until mating was achieved. If the pair did mate, the next female was selected. This process was repeated until all females had 
mated. Probabilities of mating therefore depended on the logistic functions and the length distributions of males and females.

Characteristics of this model include that females were monogamous, males were polygamous, and all females but not all males in the population mated. We initially considered a model that more explicitly mimicked spawning behavior, incorporating multiple nests per female, females potentially mating with different males for each nest, and sneaking behavior of small males. We eventually abandoned that complexity because of the lack of information on which to base model structure and parameterization. The benchmark we were striving for was a small positive correlation between the lengths of mated pairs (Kaitala and Getz [1995]). A model that more closely mimicked Chinook salmon spawning behavior that produced a similar correlation between the lengths of mated pairs might be expected to produce similar results because only the sizes and ages of a mated pair formed the input to the heritability model (see Section 2.5) and thereby controlled the size and age of individuals in subsequent generations.

2.3. Fecundity submodel. The fecundity of Chinook salmon is known to vary significantly among populations, and published data from Yukon River Chinook salmon are limited. Weidner [1972] and Skaugstad and McCracken [1991] reported data collected in the Tanana River and the Yukon River main stem in the general vicinity of the Tanana River terminus. Jasper and Evenson [2006], who described fecundity data collected from the same area, found that fecundity had declined nearly $25 \%$ from the time period in which the data reported by Skaugstad and McCracken [1991] were collected. Whether fecundity has declined, there is a high level of inter-annual variability, or there is bias in either sampling or the estimation of fecundity is unknown. However, egg samples summarized in Jasper and Evenson [2006] were frozen for some time and the physical structure of some eggs was destroyed when the eggs were thawed for processing (James Jasper, ADF\&G, Anchorage, AK, personal communication). For these reasons, we developed a fecundity model using only the data reported by Weidner [1972] and Skaugstad and McCracken [1991].

The relationship between length and fecundity was explored using a variety of both allometric and linear models. The multiplicative error structure of allometric models was inconsistent with the data, so 


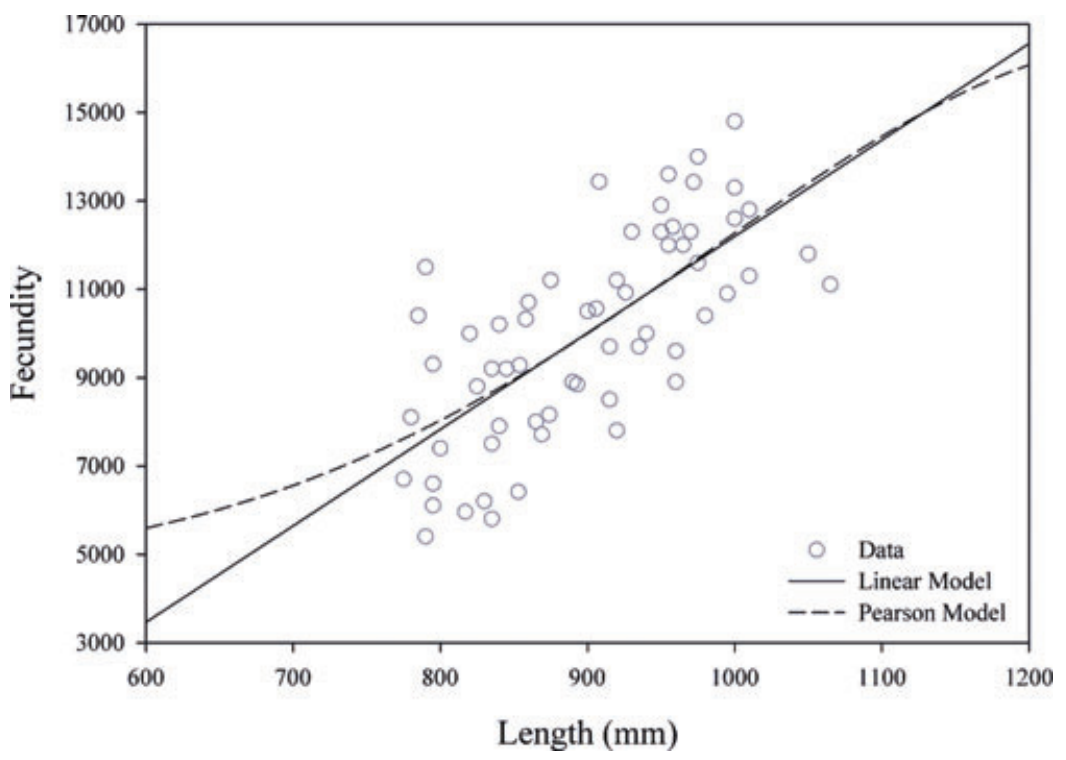

FIGURE 3. Data used to parameterize the fecundity model, with the final linear model and the Pearson model of fecundity, as a function of female length. The Pearson model was used in the computer simulation, combined with a minimum fecundity of 2,000 eggs.

linear models were utilized. The most complex linear model was a sixparameter model with a separate intercept, slope, and variance for each of the two data sources. Linear models were compared using the small sample version of the Akaike Information Criterion $\left(\mathrm{AIC}_{\mathrm{C}}\right.$, Burnham and Anderson [2002]). The preferred model had three parameters: an intercept, slope, and variance common to both data sources (Figure 3).

Preliminary investigations of the linear model revealed that randomization occasionally produced unrealistic levels of fecundity for females that were unusually small or large. A potential reduction in fish length during the simulation could increase the prevalence of this problem. Therefore, we adopted a Pearson model of fecundity that closely approximated the linear model within the observed range of the data but moderated the rate of change in fecundity for fish of unusually small 
or large length. The functional form of the Pearson model is

$$
f(x)=a+b\left[1+4(x-c)^{2}\left(2^{1 / d}-1\right) / e^{2}\right]^{-d} .
$$

Parameter values of $a=4,515, b=12,194, c=1,304, d=1,000,000$, and $e=753$ were selected to approximate the linear model (Figure 3).

Residuals from the Pearson model appeared to be homogeneous for all lengths, with a standard deviation of approximately 1,630. A Kolmogorov-Smirnov test of the normality of model residuals (Conover [1999]) was not rejected $(p>0.249)$. Therefore, fecundity was modeled as a normal random variable, with mean given by the Pearson model and a standard deviation of 1,630 . As an additional precaution against unrealistically small fecundity values, a minimum fecundity of 2,000 eggs was used in the simulation.

2.4. Survival submodels. We employed a Ricker productivity model (Ricker [1975]) as a conceptual base from which to develop survival rate submodels. The model was expressed as a function of the number of eggs deposited rather than the number of spawners:

$$
R=\frac{E}{\mu_{\mathrm{F}}} \mathrm{e}^{\alpha\left(1-\frac{E}{\mu_{\mathrm{F}} S_{\mathrm{r}}}\right)},
$$

where $E$ is the number of eggs deposited during a reproductive event, $\mu_{\mathrm{F}}$ the mean number of eggs per salmon in the unfished population, $\alpha$ the parameter controlling shape (productivity), $S_{\mathrm{r}}$ the parameter controlling equilibrium abundance in number of salmon, and $R$ the total adult return of all age classes from $E$, in numbers of salmon.

We constructed a system of "freshwater and marine survival rates" such that the total return $R$ from a deposition of $E$ eggs approximated the relationship in (3). Because $E$ tended to be quite large and only a small fraction $(R / E)$ survive to maturity, tracking the characteristics and fates of each individual would have been impractical. A common freshwater survival rate from egg deposition to ocean entry, $\lambda_{F}$, was therefore applied to all eggs deposited in a given year;

$$
\lambda_{\mathrm{F}}=\mathrm{e}^{\frac{-\alpha E}{\mu_{\mathrm{F}} S_{r}}} .
$$


Similarly, a common survival rate for the first year in the marine environment, $\lambda_{\mathrm{M} 1}$, was applied to all surviving individuals. We implemented constant sex-specific annual marine survival from age3 until maturation, denoted $\lambda_{\mathrm{MF}}$ and $\lambda_{\mathrm{MM}}$ for females and males, respectively. Therefore, $\lambda_{\mathrm{M} 1}$ was selected to produce a total return $R$ approximately equal to (3), given $\lambda_{\mathrm{F}}, \lambda_{\mathrm{MF}}, \lambda_{\mathrm{MM}}$, and the average age of return for males and females in an unfished population, $\mu_{\mathrm{AF}}$ and $\mu_{\mathrm{AM}}$

$$
\lambda_{\mathrm{M} 1}=\left(\frac{\mathrm{e}^{\alpha}}{\mu_{\mathrm{F}}}\right)\left(\frac{\lambda_{\mathrm{MF}}+\lambda_{\mathrm{MM}}}{2}\right)^{-\left(\frac{\mu_{\mathrm{AF}}+\mu_{\mathrm{AM}}}{2}-3\right)} .
$$

These survival rates were applied by multiplying the number of eggs deposited by a lognormal random variable with mean equal to $\ln \left(\lambda_{\mathrm{F}} \lambda_{\mathrm{M} 1}\right)$ and a standard deviation of $(0.8)(0.425)$, and a sample of that size was drawn from among all $E$ eggs. The total standard deviation of 0.425 was based on the level of variation observed in available productivity analyses (Evenson [2002]; JTC [2008]) used to estimate the mean age composition of parent year returns (see Section 2.1), while the multiple of 0.8 was modified from Bradford's [1995] partitioning of survival rate variance. We note that the structure of these survival rates is not explicitly intended to represent biological processes but rather to reduce the number of fish whose individual traits and fates needed to be stored in memory during a simulation (see further). The result was the number of salmon surviving from egg deposition through their first year in the marine environment, after which we established the traits and monitored the fates of individuals.

Sex composition was then established for the survivors with a single draw from a normal distribution with mean 0.50 and standard deviation 0.05 . These values were also derived from the productivity analyses referenced earlier (see Section 2.1). The age and size at maturation were also established after the first year in the marine environment (see Section 2.5). Annual sex-specific marine survival rates for age-3 to maturation were also randomized as lognormal deviates, with means $\ln \left(\lambda_{\mathrm{MF}}\right)=0.82$ and $\ln \left(\lambda_{\mathrm{MF}}\right)=0.77$ for females and males, respectively, and a common standard deviation of 1.05. These values were derived from a combination of the literature, professional judgment, and model calibration (see Section 2.7). 
To evaluate the performance of the model under a range of productivity scenarios, two values of $\alpha$ were utilized. A value of $\alpha=2.25$ was derived from the three productivity analyses available for Yukon River Chinook salmon (see Section 2.1). This represents a comparatively high level of productivity for stream-type Chinook salmon. A reduced value of $\alpha=1.5$ was selected to represent lower productivity, allowing us to explore the influence of productivity on response to fishing selection.

2.5. Heritability and fitness submodels. We used a modification of an approach developed by Ronningen [1974], Olausson and Ronningen [1975], and Réale and Roff [2001] to express offspring age and as a function of their parental phenotypes and random environmental deviations. Let $X_{\mathrm{R}}$ be a bivariate vector of the age and length phenotype of a reproducing individual, $X_{\mathrm{O}}$ a bivariate vector of the age and length phenotype of an offspring, $\mu_{\mathrm{R}}$ the expectation $E\left[X_{\mathrm{R}}\right]$, $\Sigma_{\mathrm{R}}$ the dispersion matrix $V\left[X_{\mathrm{R}}\right], \Sigma_{\mathrm{T}}$ the target dispersion matrix of age and length (see Section 2.1), $\varepsilon_{\mathrm{MP}}$ the bivariate standardized average mid-parent deviation from $\mu_{\mathrm{R}}$, a constant bias within each family, $\varepsilon_{\mathrm{G}}$ a bivariate random genetic error term common to all offspring within each family, $\varepsilon_{\mathrm{G}} \sim N\left(0, D(1 / \sqrt{2}, 1 / \sqrt{2}) \Sigma_{\mathrm{R}}\right)$, where $D(v)$ is a diagonal matrix with the vector $v$ along the diagonal, $\varepsilon_{\mathrm{E}}$ a random environmental error term for individual offspring length at maturity, $\varepsilon_{\mathrm{E}} \sim N\left(0, \Sigma_{\mathrm{T}}\right), h_{\mathrm{A}}^{2}$ the heritability of age, and $h_{\mathrm{L}}^{2}$ the heritability of length.

The bivariate phenotypes of offspring surviving to age-3 (see Section 2.4) were modeled as

$X_{O}=\mu_{\mathrm{R}}+D\left(\sqrt{h_{\mathrm{A}}^{2}}, \sqrt{h_{\mathrm{L}}^{2}}\right)\left(\varepsilon_{\mathrm{MP}}+\varepsilon_{\mathrm{G}}\right)+D\left(\sqrt{1-h_{\mathrm{A}}^{2}}, \sqrt{1-h_{\mathrm{L}}^{2}}\right) \varepsilon_{\mathrm{E}}$.

Heritability values of 0.35 and 0.34 were used for age and length, respectively; these parameter values were obtained by restricted maximum likelihood estimation from a Chinook salmon population in Washington State (Hard [2004]). We did not generate an age-structured genetic covariance matrix directly because of the lack of available information on genetic covariation among lengths expressed at different 
ages; instead, the genetic covariation of length and age was modeled by adjusting the phenotypic variances and covariances by empirically derived heritability estimates (Hard et al. [2009]). This approach may overestimate the responses in lengths expressed at younger ages to selection on large fish, but it is unlikely to misconstrue the direction of the responses to selection over the relatively short term because the estimate of genetic correlation between the traits was positive. The direction of selection on fish of particular ages is primarily dependent on the threshold sizes of fish exposed to selection and the form of the selection (e.g., disruptive versus directional).

The heritability model (10) was implemented separately for male and female offspring surviving to age-3. In order to maintain distinct age and length distributions for each sex, the mid-parent error $\varepsilon_{\mathrm{MP}}$ for each mated pair was computed after first transforming the bivariate age-length distribution of the reproducing individuals of one sex to that of the other sex using spectral and Cholesky decompositions of the variance matrices. Let $X_{\mathrm{RF}}$ and $X_{\mathrm{RM}}$ be bivariate vectors with multivariate normal densities; $X_{\mathrm{RF}} \sim N\left(\mu_{\mathrm{RF}}, \Sigma_{\mathrm{RF}}\right)$ and $X_{\mathrm{RM}} \sim N\left(\mu_{\mathrm{RM}}\right.$, $\left.\Sigma_{\mathrm{RM}}\right)$. The objective was to find the $2 \times 2$ matrix $M$ and the $2 \times 1$ vector $v$ so that the transformation $k=M X_{\mathrm{RF}}+v$ maps $X_{\mathrm{RF}}$ to the density of $X_{\mathrm{RM}}$. Note that $k$ has a multivariate normal density with mean $\mu_{k}=M \mu_{\mathrm{RF}}+v$ and dispersion $\Sigma_{k}=M \Sigma_{\mathrm{RF}} M^{T}$ (Seber [1977]). Letting $M=M_{1}^{T} M_{2}^{T}$, yields

$$
\Sigma_{k}=M_{1}^{T} M_{1}^{T} \Sigma_{\mathrm{RF}} M_{2} M_{1} .
$$

If $E_{\mathrm{RF}}$ is a matrix whose columns are formed from the eigenvalues of $\Sigma_{\mathrm{RF}}$, and $D_{\mathrm{RF}}$ is a diagonal matrix with the inverted square roots of the corresponding eigenvalues along the diagonal, that is, $D_{\mathrm{RF}}=$ $D\left(1 / \sqrt{\lambda_{1}}, / \sqrt{\lambda_{2}}\right)$, setting $M_{2}=E_{\mathrm{RF}} D_{\mathrm{RF}}$, yields

$$
\Sigma_{k}=M_{1}^{T}\left(D_{\mathrm{RF}} E_{\mathrm{RF}}^{T} \Sigma_{\mathrm{RF}} D_{\mathrm{RF}}\right) M_{1}=M_{1}^{T} M_{1}
$$

(Seber [1977]). If $M_{1}$ is the upper triangular matrix of the Cholesky decomposition of $\Sigma_{\mathrm{RF}}$, setting

$$
M=M_{1}^{T} D_{\mathrm{RF}} E_{\mathrm{RF}}^{T}
$$


yields the desired dispersion matrix $\Sigma_{k}=\Sigma_{\mathrm{RM}}$ and

$$
v=\mu_{\mathrm{RM}}-M \mu_{\mathrm{RF}},
$$

properly centers the density; $\mu_{k}=\mu_{\mathrm{RM}}$. Note that the transformation, as presented, maps an observation from the density of reproducing females to that of reproducing males, although the inverse transformation proceeds symmetrically.

All error terms were randomly drawn from sex-specific bivariate normal distributions. A single random genetic error term $\varepsilon_{\mathrm{G}}$ was drawn for all offspring of a given sex within each family. A random environmental error term $\varepsilon_{\mathrm{E}}$ was then drawn for each individual offspring, and its phenotype (maturation age and length) was thereby established.

Application of the heritability model was followed by what we term a "fitness model." This model was conceptualized as a selective force operating on immature offspring that would tend to disfavor individuals whose phenotypes deviated greatly from the target mean age and length in an unfished population (Law [1991]; Hard [2004]; see Section 2.1). It therefore represented weak stabilizing selection toward a naturally optimum length and age, that is, a force that might reflect natural or sexual selection on size and age in the population.

The fitness submodel for an individual of age $A$ and length $L, f(A, L)$, was constructed as a bivariate normal density (Kotz et al. [2000]) scaled to have a maximum of 1.0, with mean and variance equal to one and seven times the unfished mean and variance, respectively (Hard [2004]); that is,

$$
\begin{aligned}
f(A, L)= & \exp \left\{-\frac{1}{7(2)\left(1-\rho^{2}\right)}\left[\left(\frac{A-\mu_{A}}{\sigma_{A}}\right)^{2}\right.\right. \\
& \left.\left.-2 \rho\left(\frac{A-\mu_{A}}{\sigma_{A}}\right)\left(\frac{L-\mu_{L}}{\sigma_{L}}\right)+\left(\frac{L-\mu_{L}}{\sigma_{L}}\right)^{2}\right]\right\} .
\end{aligned}
$$

The variance multiplier of seven was established during model calibration (see Section 2.7) as the value that stabilized the population without reducing variances below the target levels previously described (see Section 2.1). The effect is a selection function whose value is high 


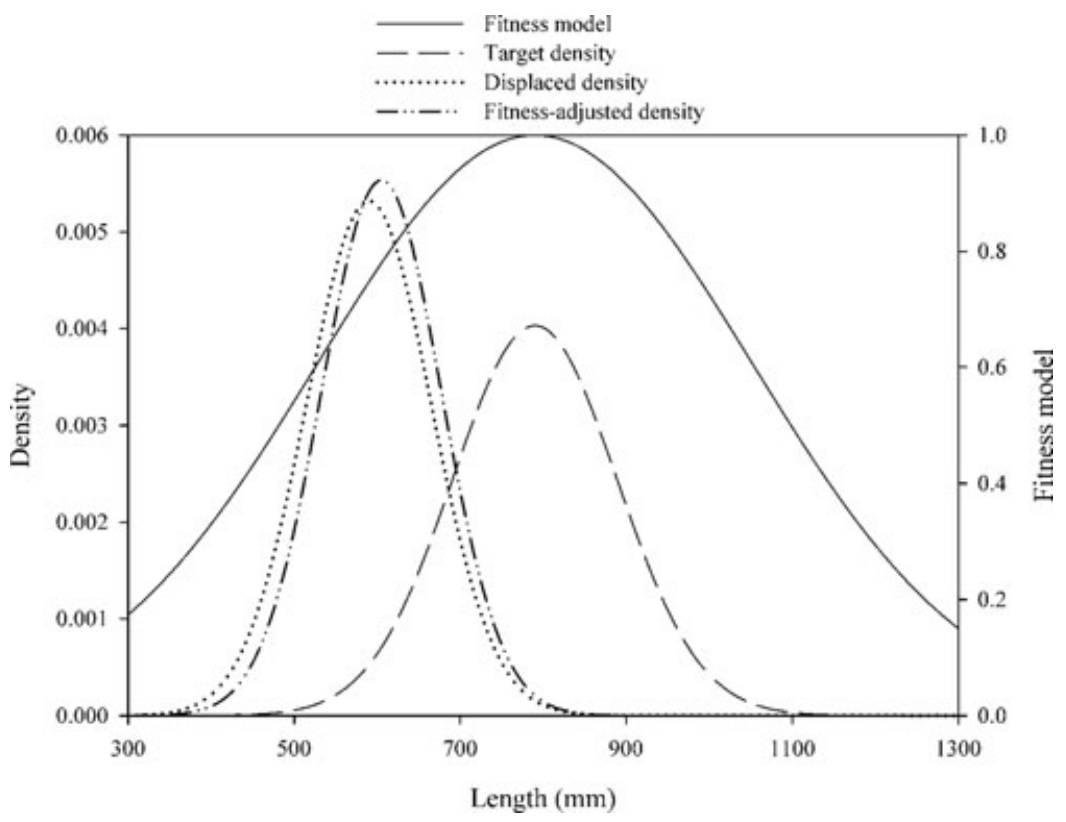

FIGURE 4. A hypothetical example in two dimensions illustrating the influence of the fitness model on length.

over much of the natural range of length and age, but declines more steeply as deviations from the optimal increase. The influence of the fitness model on the evolution of length and age is difficult to visualize in three dimensions, so we provide a two-dimensional hypothetical example for length alone to illustrate its use and the magnitude of its effect (Figure 4). In this example, the fitness submodel transforms a hypothetical displaced (fished) length density to one slightly more similar to the mode of the fitness function and the target (unfished) length density.

The fitness model was implemented by drawing a sample of offspring, equivalent in size to the number of individuals surviving to age-3, from the output of the heritability model using the values of the fitness model as probabilities of selection. The result of this sampling process was a collection of individuals whose lengths and ages at maturation were 
established, although subject to additional annual marine mortality until maturation (see Section 2.4). Surviving offspring maturing in a common year were aggregated to form annual runs.

2.6. Exploitation submodel. The exploitation submodel was constructed from three components: an escapement goal (desired number of reproducing salmon), a level of management precision, and an exploitation parameter. A target escapement goal, $S_{\mathrm{G}}$, was established as a multiple, $k$, of the escapement that maximizes sustainable average yield, $S_{\mathrm{MSY}}$ (Ricker [1975]; see Section 3); 0.5, 1.0, and 1.5 were used as values of $k$ to represent a range from underescapement to overescapement relative to $S_{\mathrm{MSY}}$. Given a target escapement goal $S_{\mathrm{G}}=k S_{\mathrm{MSY}}$, an escapement goal range of $0.8 S_{\mathrm{G}}$ to $1.6 S_{\mathrm{G}}$ was established (Eggers [1993]) for each simulation. The objective was to manage toward the lower end of the range in years of small runs and toward the upper end of the range in years of large runs.

The ability of management to assess run size and manage accordingly was modeled as a uniform random variable (Johnson et al. [1995]) centered on the true run size. Two levels of management precision were utilized. Under more precise management, managers were able to assess the size of a run within $15 \%$ of the true run size, while run size was assessed within $30 \%$ of the true run size under less precise management.

Given a simulated (true) run size, a randomly generated assessment of the run size $(N)$ within the bounds of management precision, and an escapement goal, an exploitation model was used to establish a catch level. If a run was assessed to be less than $0.8 S_{\mathrm{G}}$, no fish were taken. If a run was assessed to exceed $0.8 S_{\mathrm{G}}$, a constant exploitation rate $\gamma$ was applied to the portion of the assessed run in excess of $0.8 S_{\mathrm{G}}$. The escapement goal therefore increased linearly between $0.8 S_{\mathrm{G}}$ and the maximum of $1.6 S_{\mathrm{G}}$ as the assessed run size increased above $0.8 S_{\mathrm{G}}$. For assessed runs sufficiently large to achieve the maximum escapement of $1.6 S_{\mathrm{G}}$, the remainder of the run was apportioned to the catch. Two values of $\gamma$ were employed, with $\gamma=0.85$ representing a more aggressive fishery on small and medium sized runs than $\gamma=0.5$. The mean exploitation rates on the entire run are presented in Figure 5; the random error in run size assessment created variability about the mean. 


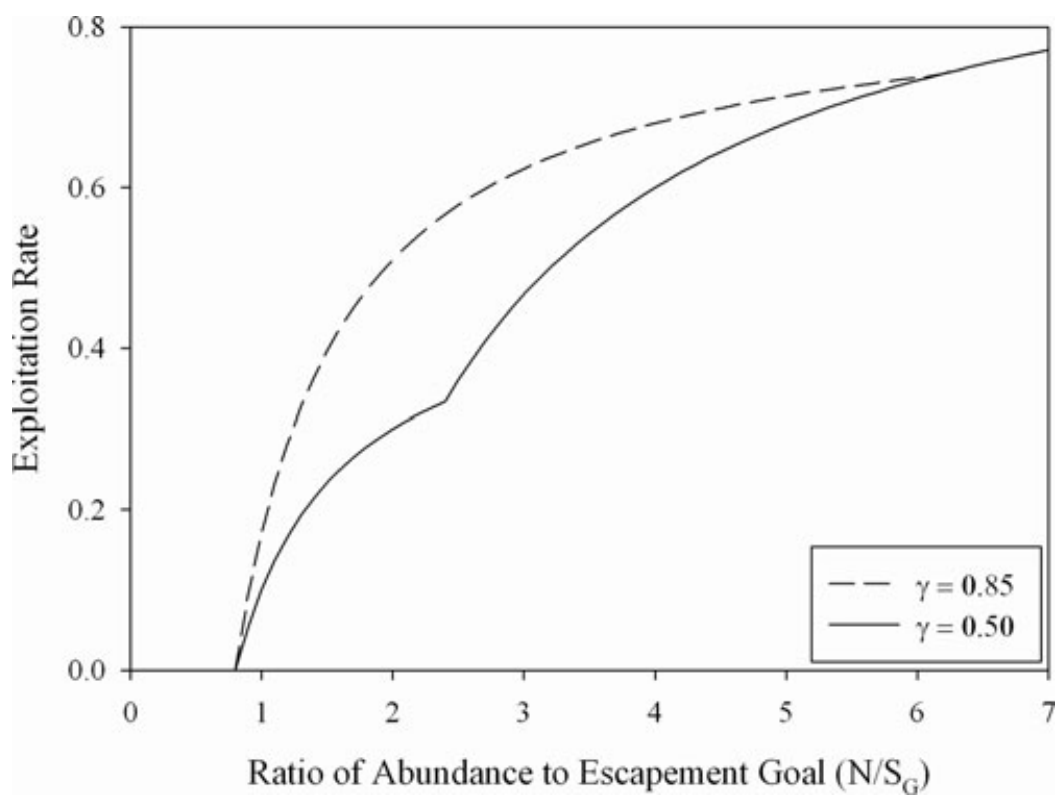

FIGURE 5. The mean exploitation rate under each of the two exploitation models.

Once a catch level was established, each fish in the run was assigned a probability of capture using the length-based relative net selectivity estimates of Bromaghin [2005] as sampling probabilities:

$$
\begin{aligned}
s(x)= & \left(1+\frac{\lambda^{2}}{4 \theta^{2}}\right)^{\theta}\left[1+\frac{\left(x-\frac{\sigma \lambda}{2 \theta}-\tau\right)^{2}}{\sigma^{2}}\right]^{-\theta} \\
& \times \exp \left\{-\lambda\left[\tan ^{-1}\left(\frac{x-\frac{\sigma \lambda}{2 \theta}-\tau}{\sigma}\right)+\tan ^{-1}\left(\frac{\lambda}{2 \theta}\right)\right]\right\},
\end{aligned}
$$

where $x$ is the ratio of length to mesh perimeter, 381.0 or 431.8 for 7.5 in. or 8.5 in. mesh, respectively, $\tau=1.920, \sigma=0.204, \theta=0.622, \lambda=$ -0.547 , and $\omega=0.031$. Incorporating knowledge of gear selectivity into investigations of fishery-induced evolution in this fashion is consistent 
with the suggestions of Kuparinen et al. [2009]. A catch of the determined size was then removed from the run using unequal-probability sampling without replacement. Catch levels were always achieved, with realized escapements varying commensurate with error in assessing run size. However, realized exploitation rates on the entire run were capped at 0.95 to prevent all fish from being caught, which could occur in rare years of very large runs that were overestimated by an amount greater than the escapement goal. Fish that were not caught comprised the reproductive population for that year and were used to generate offspring to return in subsequent years.

2.7. Model calibration. When independently developed submodels are linked together in the fashion described earlier, they may interact in unexpected ways and model outputs trend or otherwise perform unexpectedly. For that reason, the model was calibrated (e.g., Beaudouin et al. [2008]) to be temporally stable by monitoring a subset of model outputs judged to be of greatest importance. Outputs that were most closely monitored during calibration include the mean and variance of age at maturation for each sex, the mean and variance of length at maturation for each sex, age composition for each sex, and the mean and variance of annual run sizes. Population dynamics in the absence of a fishery were simulated and the averages of these demographic characteristics were computed and compared with desired target levels. When differences occurred, model parameters were changed slightly and the process was repeated. We implemented this approach because the availability of reliable data to support global calibration via numerical optimization or other techniques (Ginot et al. [2006]) was deemed insufficient. Many of the submodels interacted nonlinearly, and a change that moved one characteristic closer to its target value often moved a second characteristic further away. Model calibration was therefore an iterative process, during which we strove to balance opposing tendencies of the model. Parameters that were changed during model calibration are presented in Table 4.

3. Planned simulations. We conducted a preliminary ("burnin") simulation to randomize the starting point for all subsequent simulations; this was done independently for the low-productivity 
$(\alpha=1.50)$ and high-productivity $(\alpha=2.25)$ simulations. The population was initialized with a generation of escapements equal to the equilibrium abundance level of $S_{\mathrm{r}}=10,000$, and population dynamics were simulated for 2,200 years. Results from the first 200 years were discarded to disassociate results from the equilibrium starting point of 10,000 spawners, and the results from the remaining 2,000 years were randomized into 250 blocks of 8 years of data. Each block was randomly assigned to initialize one of the 250 replications comprising each simulation. In addition, the last 2,000 years of data from each productivity level were used to estimate the level of escapement maximizing sustained yield ( $\left.S_{\mathrm{MSY}}\right)$ using the approximation of Hilborn [1985] that incorporates the expectation of a lognormal variate. $S_{\mathrm{MSY}}$ was estimated to be 3,505 in the high-productivity case and 4,014 in the low-productivity case; these values were used to establish escapement goals (see Section 2.6).

We initially conducted a set of 24 simulations, formed by the combinations of productivity (2 levels) and the management controls of exploitation $\gamma$ (2 levels), management precision (2 levels), and an escapement goal (3 levels). In all of these simulations, catches were taken using the selectivity of an 8.5-in gillnet (Bromaghin [2005]). In addition, a no-fishing control simulation was conducted for each of the two levels of productivity (Table 5). Each simulation consisted of 250 replications of modeling population dynamics for 200 years, or 25 complete generations based on a maximum age of 8 years. Information from the last 8 years of each replication was saved so that the simulation could be continued for additional years.

We selected the mean length of all fish in a run to illustrate the temporal patterns observed in response to size-selective exploitation. Mean length was computed for each year in each of the 250 replications within a simulation and then averaged across replications for each year. The magnitude of fishery selection over time was explored via mean selection differentials (Law [1991]; Swain et al. [2007]). We again use length as a representative example, computing the selection differential by subtracting the mean length in the run from the mean length in the escapement (reproducing individuals, postfishery). Negative values of the selection differential therefore reflect the case where mean length is greater in the run than in the escapement. Selection differentials were computed for each year in each replication, and mean selection 
TABLE 5. Parameter values that varied among the 26 planned simulations.

\begin{tabular}{|c|c|c|c|c|}
\hline Simulation & Productivity & Exploitation & $\begin{array}{c}\text { Management } \\
\text { precision }\end{array}$ & $\begin{array}{c}\text { Escapement } \\
\text { goal }\end{array}$ \\
\hline 1 & 2.25 & & No fishing control & \\
\hline 2 & 2.25 & 0.85 & $\pm 30 \%$ & 0.50 \\
\hline 3 & 2.25 & 0.85 & $\pm 30 \%$ & 1.00 \\
\hline 4 & 2.25 & 0.85 & $\pm 30 \%$ & 1.50 \\
\hline 5 & 2.25 & 0.50 & $\pm 30 \%$ & 0.50 \\
\hline 6 & 2.25 & 0.50 & $\pm 30 \%$ & 1.00 \\
\hline 7 & 2.25 & 0.50 & $\pm 30 \%$ & 1.50 \\
\hline 8 & 2.25 & 0.85 & $\pm 15 \%$ & 0.50 \\
\hline 9 & 2.25 & 0.85 & $\pm 15 \%$ & 1.00 \\
\hline 10 & 2.25 & 0.85 & $\pm 15 \%$ & 1.50 \\
\hline 11 & 2.25 & 0.50 & $\pm 15 \%$ & 0.50 \\
\hline 12 & 2.25 & 0.50 & $\pm 15 \%$ & 1.00 \\
\hline 13 & 2.25 & 0.50 & $\pm 15 \%$ & 1.50 \\
\hline 14 & 1.50 & & No fishing control & \\
\hline 15 & 1.50 & 0.85 & $\pm 30 \%$ & 0.50 \\
\hline 16 & 1.50 & 0.85 & $\pm 30 \%$ & 1.00 \\
\hline 17 & 1.50 & 0.85 & $\pm 30 \%$ & 1.50 \\
\hline 18 & 1.50 & 0.50 & $\pm 30 \%$ & 0.50 \\
\hline 19 & 1.50 & 0.50 & $\pm 30 \%$ & 1.00 \\
\hline 20 & 1.50 & 0.50 & $\pm 30 \%$ & 1.50 \\
\hline 21 & 1.50 & 0.85 & $\pm 15 \%$ & 0.50 \\
\hline 22 & 1.50 & 0.85 & $\pm 15 \%$ & 1.00 \\
\hline 23 & 1.50 & 0.85 & $\pm 15 \%$ & 1.50 \\
\hline 24 & 1.50 & 0.50 & $\pm 15 \%$ & 0.50 \\
\hline 25 & 1.50 & 0.50 & $\pm 15 \%$ & 1.00 \\
\hline 26 & 1.50 & 0.50 & $\pm 15 \%$ & 1.50 \\
\hline
\end{tabular}

Note: The value listed for the escapement goal is a multiple of the escapement that maximizes sustained yield, $S_{\mathrm{MS}}$. In all cases, except the two no-fishing control simulations, catches were taken with 8.5 -in mesh gill nets. 
differentials were computed by averaging over all replications within a simulation.

3.1. Results of planned simulations. Population demographics were temporally stable in the two control simulations with no fishing (Simulations 1 and 14; Table 5), providing evidence of model stability in the absence of fishing; it was such stability that we were seeking during model calibration. Conversely, population demographics showed trends under all fishing scenarios considered in the planned simulations, with the population shifting toward smaller, younger fish in response to the selective removal of large fish.

In nearly all fishing scenarios considered, mean length displayed a consistent decline for approximately 50 years, after which the rate of decline tended to moderate (Figure 6). In most cases, mean length was approximately stable by Year 100. Mean length decreased by approximately one third in the high-productivity simulations, while the decline was somewhat less, approximately one quarter, in the low-productivity simulations.

The observed reduction in length resulted from a combination of a reduction in mean age as well as a reduction in length at age. Mean age responded similarly to mean length over time. After 200 years of selective exploitation, mean age declined by more than 1 year and the age- 7 and age- 8 individuals were essentially extirpated in nearly all of the simulations. There were corresponding declining trends in correlated traits, such as fecundity and total egg deposition.

Two exceptions to this general pattern were observed in the lowproductivity simulations 20 and 26 (Table 5; Figure 6). The fisheries in these simulations were the most conservative among all scenarios considered, with the largest escapement goal of $1.5\left(S_{\mathrm{MSY}}\right)$ and the lowest exploitation parameter of $\gamma=0.50$. In these cases, mean length and age declined throughout the 200 years of the simulation, but remnants of the oldest age classes persisted. In the corresponding simulations with high productivity (Simulations 7 and 13), mean length also declined more slowly than in the other high-productivity fishing scenarios. However, in these cases, mean length eventually stabilized at a level somewhat greater than that observed in the other fishing scenarios. 


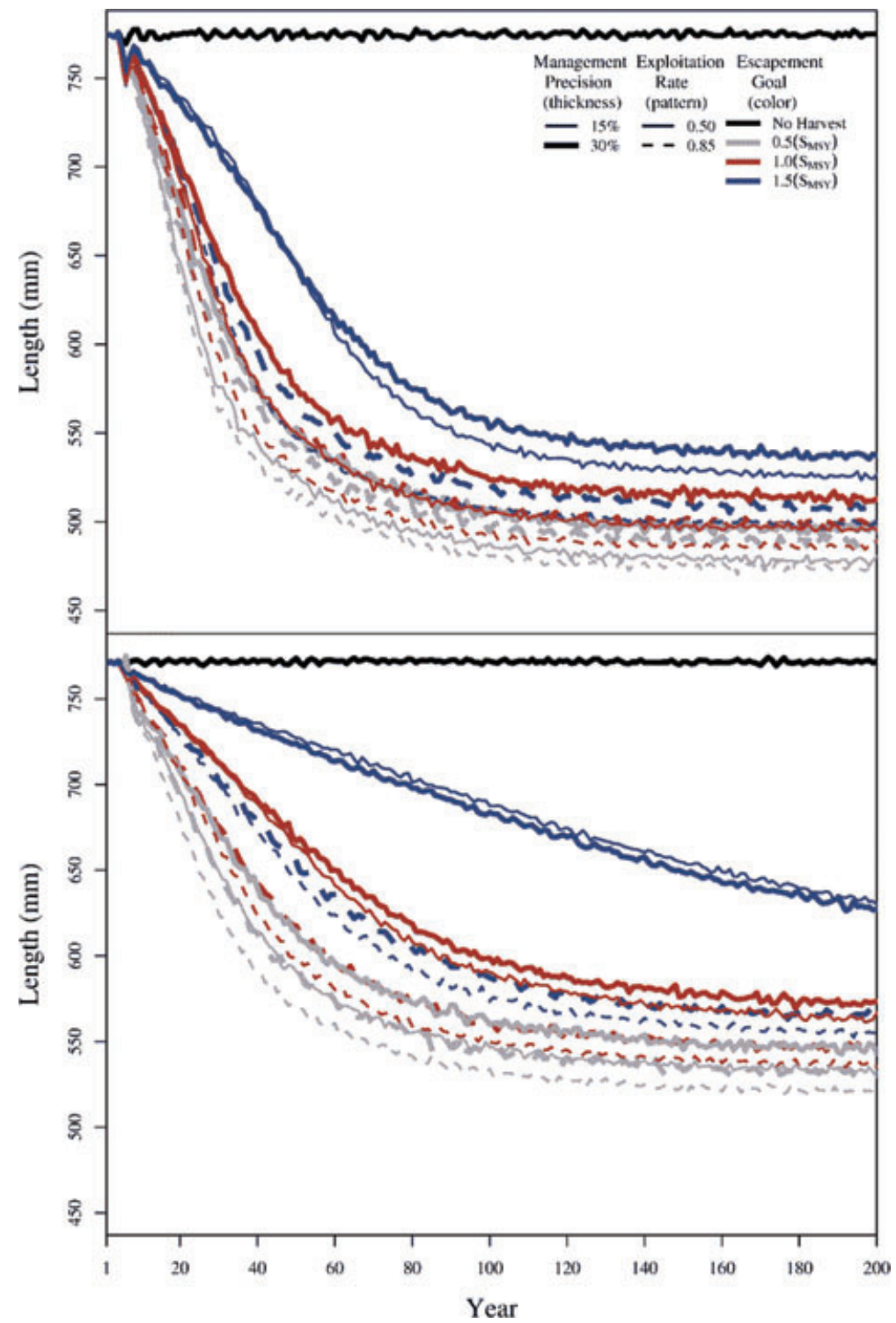

FIGURE 6. Mean length of all fish in a run over time in the high (top) and low (bottom) productivity simulations. 
In the initial years of the fishery, the length of fish in the run declined in response to selective removal of large fish. The mean length of fish in the catch also declined but less sharply as the fishery continued to be selective for the large fish remaining in the runs. The result was an initial decline in the mean selection differential (Figure 7). As large fish became increasingly rare in the population, the mean selection differential tended to increase and stabilize as the demographic composition of the modeled population reached a new equilibrium. The strength of this pattern was more pronounced in the high-productivity simulations. Notable exceptions were Simulations 20 and 26 (Table 5), in which the modeled population had not stabilized by Year 200. In these cases, the mean selection differentials declined throughout the 200 years of the simulation (Figure 7). A nearly identical pattern was observed in the mean selection differentials for age (results not shown).

Of the three parameters characterizing fishery management, the escapement goal and the exploitation parameter $\gamma$ had the greatest influence over the size and age at which the demographic composition stabilized. Precision in accessing run abundance primarily influenced the variability of results across replications of a simulation. To illustrate the relative influence of these inputs, we selected two measures of population productivity, the total number of eggs deposited in Year 200 and estimates of the productivity parameter $\alpha$ (4), from among all model outputs. The parameter $\alpha$ was estimated using spawner-return pairs from the last 100 years of each simulation, a period of time during which most populations had reached an equilibrium (Figure 6), using linear regression and the lognormal error adjustment (Hilborn [1985]). The reduced size of females led to commensurate reductions in mean fecundity and therefore to the total number of eggs deposited (Figure 8, top). Egg deposition declined by approximately $50 \%$ or more in all 24 simulations with fishing. It is not surprising that management controls that tended to maintain larger escapements also resulted in more eggs being deposited. However, a more conservative fishery on small to medium runs, as represented by the exploitation parameter $\gamma=0.50$ (Figure 5), was also strongly and positively associated with egg deposition. Estimates of the productivity parameter $\alpha$ displayed a similar pattern (Figure 8, bottom). Apparent productivity declined under all simulations with fishing. As with egg deposition, management 


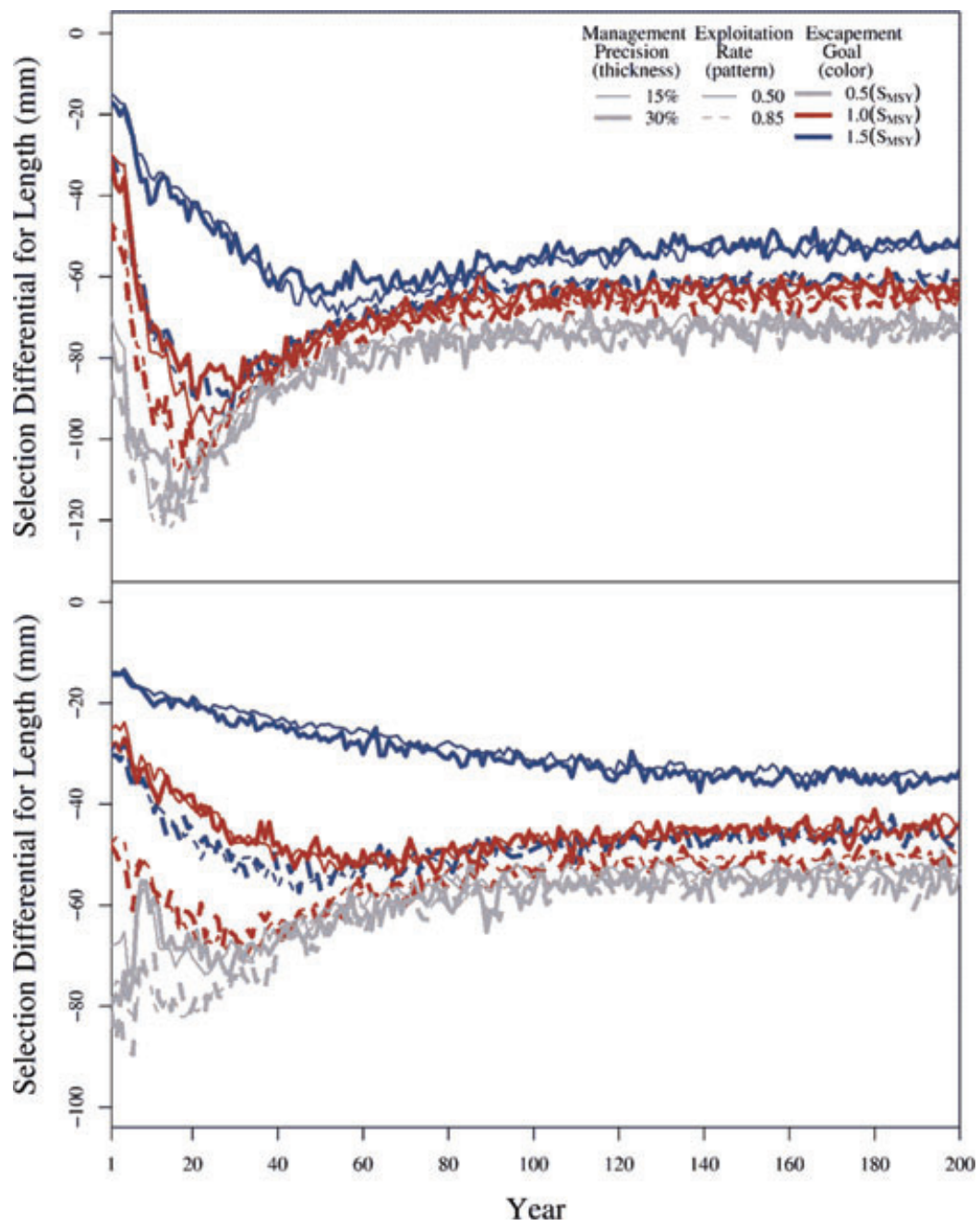

FIGURE 7. Mean selection differentials over time in the high (top) and low (bottom) productivity simulations. 


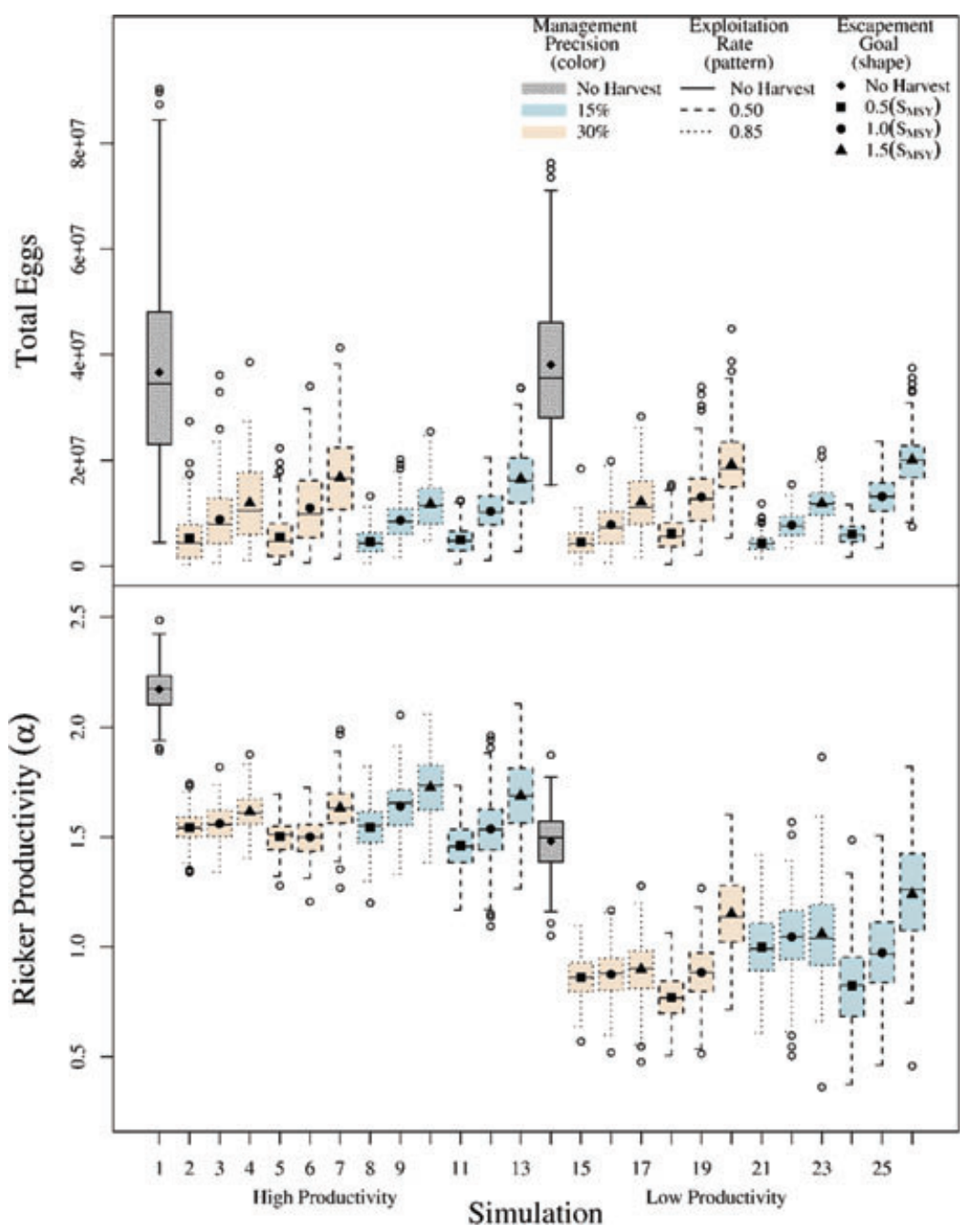

FIGURE 8. Box plots of the total number of eggs deposited (top) and estimates of the productivity parameter of the Ricker model (bottom) constructed from the 250 replications observed in Year 200. 
strategies that maintain larger escapements also maintained higher apparent productivity.

4. Alternative fishing simulations. A subset of the planned simulations was selected to investigate the response of the modeled population to alternative fishing scenarios, intended to represent potential management responses to a perceived decline in fish length or age. Because of the similarity of the results obtained under the two levels of management precision, only simulations with a management precision of $15 \%$ were selected. For each of the high- and low-productivity scenarios, we selected one simulation in which the population response had been among the largest (Simulations 8 and 21; Table 5) and a second in which the response had been among the smallest (Simulations 13 and 26; Table 5).

Each of these four original simulations was extended an additional 200 years, for a total of 400 years, under a variety of alternative fishing scenarios. In one suite of scenarios, the exploitation rate was held at its original value while the mesh size was reduced from 8.5 to $7.5 \mathrm{in}$. In a second suite of scenarios for Simulations 8 and 21 only, for which the original exploitation parameter had been $\gamma=0.85$, the mesh size was reduced to $7.5 \mathrm{in}$. and the exploitation parameter was reduced to $\gamma=0.50$. In both suites of scenarios, each simulation was extended with the original escapement goal and with increased escapement goals in increments of $0.5\left(S_{\mathrm{MSY}}\right)$ up to a maximum of $3.5\left(S_{\mathrm{MSY}}\right)$, or until the modeled population was observed to make substantial progress in recovery toward the original unfished demographic composition. Fishing was stopped completely in a third scenario. Mean length was again selected to represent the results of the alternative fishing simulations. For each of the four original simulations, box plots of mean length were constructed at 50-year intervals using the results of the 250 replicates of the original simulation and each alternative fishing simulation.

4.1. Results of alternative fishing simulations. Simulation 8 was a high-productivity simulation conducted with a mesh size of 8.5 in., an exploitation parameter of $\gamma=0.85$, and an escapement goal of $0.5\left(S_{\mathrm{MSY}}\right)$ (Table 5$)$. Alternative fishing simulations were conducted for an additional 200 years using a reduced mesh size of 7.5 in. and the original exploitation rate of $\gamma=0.85$. A simulation was conducted 
at the original escapement goal of $0.5\left(S_{\mathrm{MSY}}\right)$ and at each increment of $0.5\left(S_{\mathrm{MSY}}\right)$. However, a substantial response in mean length was not obtained at even the largest escapement goal considered, 3.5 $\left(S_{\mathrm{MSY}}\right)$, a level of escapement well above the equilibrium value of 10,000 . When the exploitation parameter was also reduced from $\gamma=0.85$ to $\gamma=$ 0.50 , a substantial response in mean length and age was observed at an escapement goal of $2.5\left(S_{\mathrm{MSY}}\right)$.

Simulation 13 was a high-productivity simulation conducted with a mesh size of 8.5 in., an exploitation parameter of $\gamma=0.50$, and an escapement goal of 1.5 $\left(S_{\mathrm{MSY}}\right)$ (Table 5). Alternative fishing simulations were conducted for an additional 200 years using a reduced mesh size of $7.5 \mathrm{in}$. and the original exploitation rate of $\gamma=0.50$. A simulation was conducted at the original escapement goal of $1.5\left(S_{\mathrm{MSY}}\right)$ and at each increment of $0.5\left(S_{\mathrm{MSY}}\right)$. A substantial response in mean length and age was obtained at an escapement goal of $2.5\left(S_{\mathrm{MSY}}\right)$, a value approximately $10 \%$ less than the equilibrium value of 10,000 .

Simulation 21 was a low-productivity simulation conducted with a mesh size of 8.5 in., an exploitation parameter of $\gamma=0.85$, and an escapement goal of $0.5\left(S_{\mathrm{MSY}}\right)$ (Table 5$)$. Alternative fishing simulations were conducted for an additional 200 years using a reduced mesh size of 7.5 in. and the original exploitation rate of $\gamma=0.85$. A simulation was conducted at the original escapement goal of $0.5\left(S_{\mathrm{MSY}}\right)$ and at each increment of $0.5\left(S_{\mathrm{MSY}}\right)$. A substantial response in mean length and age was not obtained until the escapement goal was increased to $2.5\left(S_{\mathrm{MSY}}\right)$, a level of escapement approximately equal to the equilibrium value of 10,000 . When the exploitation parameter was also reduced from $\gamma=$ 0.85 to $\gamma=0.50$, a substantial response in mean length and age was observed at a lower escapement goal of 1.5( $S_{\mathrm{MSY}}$ ) (Figure 9).

Simulation 26 was a low-productivity simulation conducted with a mesh size of $8.5 \mathrm{in}$., an exploitation rate of $\gamma=0.50$, and an escapement goal of $1.5\left(S_{\mathrm{MSY}}\right)$ (Table 5$)$. This is one of the simulations in which the modeled population had not yet reached a new equilibrium after initiation of fishing (Figure 6) and a remnant number of older, larger fish remained in the population. An alternative fishing simulation was conducted for an additional 200 years using a reduced mesh size of $7.5 \mathrm{in}$. and the original exploitation rate of $\gamma=0.50$. In this case, the reduction in mesh size alone was sufficient to initiate a recovery in mean length and age without increasing the escapement goal. 


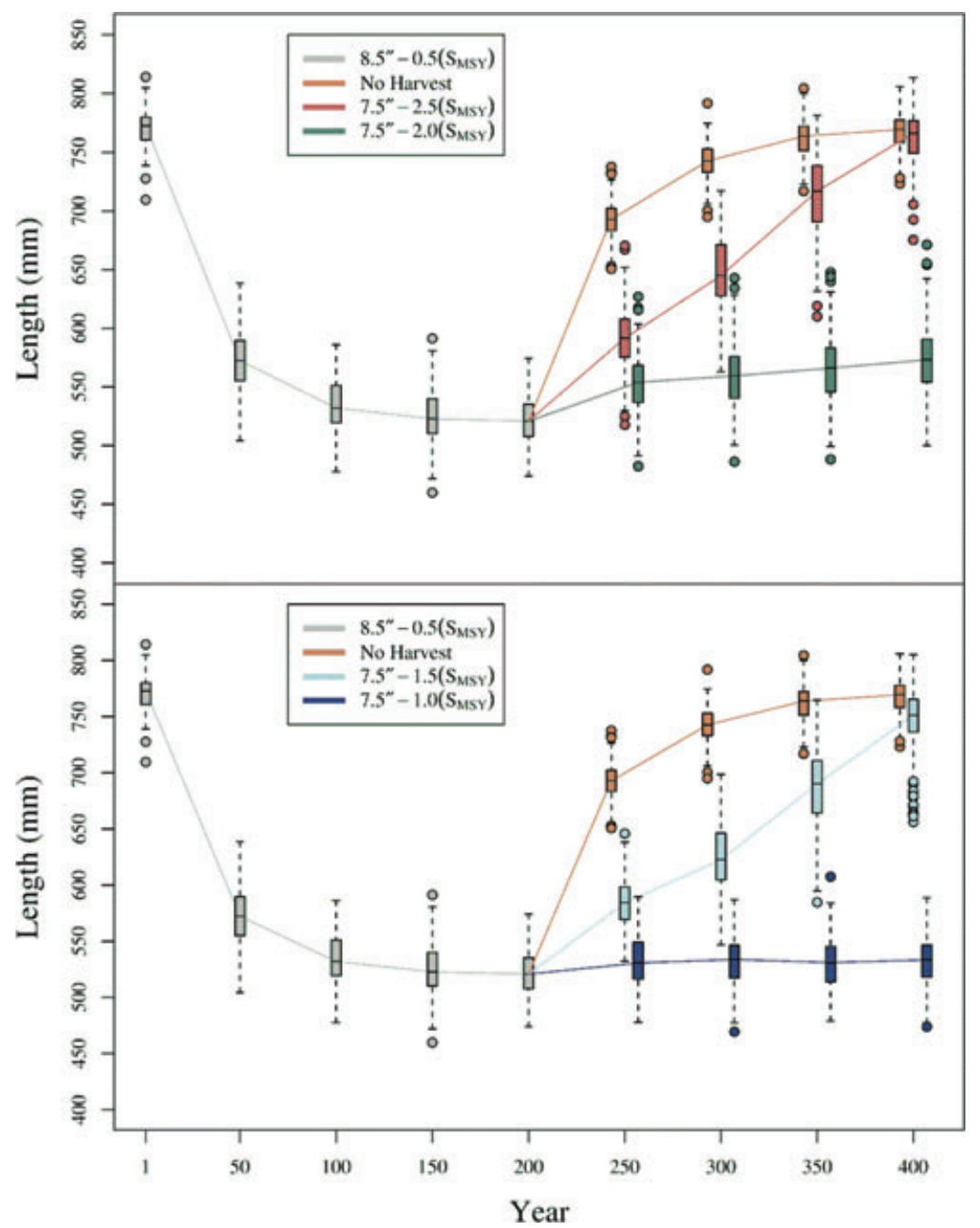

FIGURE 9. Box plots of mean length observed in 250 replications every 50 years showing the interaction between the escapement goal and high (top) and low (bottom) levels of exploitation. 
5. Discussion. Most northern populations of Chinook salmon have not experienced the substantial and prolonged habitat degradation and major impediments to freshwater migration to the extent southern populations have been subjected. The productivity of some populations was undoubtedly reduced, severely and at least temporarily, by gold dredging and other mining activity, particularly in the first portion of the $20^{\text {th }}$ century. However, the selective exploitation of large individuals has been a persistent pressure on many populations for generations. The declines in average weight and length documented by Bigler et al. [1996], the reduced frequency of large $(\geq 900 \mathrm{~mm})$ Chinook salmon in several spawning populations (Hyer and Schleusner [2005]), unexpectedly low abundance since the late 1990s, and a widespread public perception that mean size and age have declined have precipitated concern regarding the future of Chinook salmon populations and fisheries in western Alaska, especially in the Yukon River. Whether these apparent changes have primarily resulted from fishery-induced adaptation or environmental factors that affect growth and maturation is the subject of considerable controversy, and at present neither of these putative factors can be ruled out.

The myriad of interacting fishery and natural selective pressures operating on wild populations and the lack of experimental controls makes it a challenge to definitively address these questions using empirical observations. For that reason, we chose to probe one aspect of this controversy by investigating the potential for selective exploitation to alter population productivity and demographics using computer simulation. We developed an individual-based, stochastic model that integrates population dynamics and evolution through the inheritance of correlated phenotypes (length and age at maturation). Because of the current concern regarding Yukon River Chinook salmon, some components of the model were parameterized to approximate their recent demography and life history. We sought to identify general patterns of response to selection using approaches commonly used in analyses of phenotypic evolution to inform fisheries managers about the potential consequences of selective fishing practices.

There are several advantages to initially approaching a problem through computer simulation (e.g., Elphick [2008]). Use of a model allows one to isolate individual factors or combinations of factors and investigate their influence on the characteristics of interest while 
holding potentially confounding factors constant and thereby eliminating their influence. Issues such as sampling bias and extra variation or bias caused by unidentified factors, which are often troublesome in analyses of empirical data, can be avoided completely. The outcome of a model can be replicated, and the range, variation, and mean of outcomes observed across replications can be informative with respect to the reliability of predictions. Because of these advantages, computer simulation can efficiently identify important explanatory factors and predict the type of response they will likely produce. An additional advantage of computer modeling is that a complex biological system can be represented by a model that is comparatively simple. This advantage can also be a limitation; a model is a caricature of reality and its utility depends on the validity of the assumptions made during model construction.

Our model encapsulates a number of assumptions via model structure and parameterization about the life history and evolutionary responsiveness of Chinook salmon. Most of the demographic, phenotypic, and productivity components were based upon empirical observations and so are expected to provide reasonable approximations. Similarly, the estimates of net selectivity used in the simulation are based on a large dataset collected over many years (Bromaghin 2005) and are expected to provide a reasonable approximation of selectivity in a gillnet fishery. There is no doubt that length, age, and other key traits are heritable in Chinook salmon and would therefore respond to selection (Carlson and Seamons [2008]). We parameterized this model with empirical estimates of heritability and correlation for age and length in a freely migrating ocean-type population of Chinook salmon from Washington State; whether these values are representative of northern stream-type Chinook salmon is unknown. Very few such estimates exist, and those that are available are very close to those used in our model $(0.3-0.5$ for age and $0.3-0.4$ for length). The estimates used in our model are near the lower end of these ranges, in part because of the restricted maximum likelihood estimator used, which minimizes the upward bias inherent in other estimators when breeding designs are unbalanced. Although we did not evaluate model results with lower and higher heritabilities, modifying heritabilities would change the rate rather than the magnitude or direction of the response to selection (Hard [2004]; Eldridge et al. [2010]) and would not alter primary conclusions. 
The structure of some submodels was less firmly founded on either empirical observations, biological theory, or tested models. For example, the mating behavior of Chinook salmon is known to be more complex than the model we implemented (e.g., Berejikian et al. [2000]); this component of the model is perhaps most in need of additional development. The combination of a positive correlation among the lengths of mated pairs, fecundity increasing with female size (unequal family size), and the co-heritability of traits necessitated a slight departure from the heritability model of Ronningen [1974], Olausson and Ronningen [1975], and Réale and Roff [2001] to achieve a stable population. Our incorporation of a fitness submodel was an attempt to impart resilience to selection imposed by fishing via stabilizing natural or sexual selection. This submodel had a strong influence on the magnitude of the decline in length and age prior to stabilization. Resilience to selection has not, to our knowledge, been estimated from empirical data on salmon, and our parameterization was determined during model calibration. The lack of information on resilience to selection reduces the ability of our model to make absolute predictions regarding the magnitude of a response to selective exploitation.

An additional feature of the model that limits its ability to make absolute predictions is the exploitation model. This component of the model is more simplistic than most wild Chinook salmon fisheries, and the Yukon River fishery is more complex than most wild salmon fisheries (e.g., Criddle [1996]). The complexity of the Yukon River fishery is such that developing a realistic model would be a challenging undertaking, and we did not explicitly attempt to mimic its dynamics in the current version of the model. Consequently, the output of the current model is thought to overestimate the magnitude of any fishery-induced adaptation in the existing fishery. This component of the model merits additional attention if subsequent versions of the model are developed to improve predictive capability.

Other prominent assumptions include that length and age at maturation are genetically linked, that genetic characteristics underlying these traits are not rapidly eroded by selection, and that productivity is stationary and responds predictably to changes in spawner abundance and composition. The linkage between lengths at age was explored in a deterministic model by Eldridge et al. [2010], who showed that the genetic correlation between these traits could have a substantial effect 
on the direction as well as the rate of evolutionary response to sizeselective harvest in Chinook salmon. Because some of these features of the model are not founded on empirical observations, their suitability is difficult to assess.

Within a stationary environment, an unexploited population of Chinook salmon should display temporally stable demographics. Our approach to dealing with uncertainties regarding model suitability and the lack of information on important model inputs was to modify initial inputs until such stability was obtained. Model calibration was challenging because of the nonlinear interaction of some model components, especially the interaction among inheritance of length and age, the dependence of fecundity on length, and the assortative mating model. Although we succeeded in producing stability and realistic demographic and life history characteristics in the unexploited population, our methods may not reflect processes that produce these features in wild populations. Nevertheless, we believe that this model represents a reasonable first attempt to develop such an individual-based model for Chinook salmon and that the model successfully predicts the direction, and possibly the temporal pattern, of fishery-induced evolution. For example, model outputs are qualitatively similar to those of a deterministic model of fishery-induced evolution in Chinook salmon (Hard et al. [2009]; Eldridge et al. [2010]). That our model is based upon selection for a single trait (length) is an additional reason to suspect that it overestimates the magnitude of the effects (Riddell [1986]). Indeed, the magnitude of the response depends directly on the strength of stabilizing natural and sexual selection, a multifaceted factor for which we have no information. Even so, a model of this type appears to have considerable potential, and we expect that future improvements to model structure will provide additional insights into the dynamics of fishery-induced adaptation in Pacific salmon.

Our results suggest that size-selective fisheries for Chinook salmon employing large-mesh gillnets impose directional selection against larger fish and could shift population demography and reduce productivity through evolution of length and age at maturation within ten generations. In most scenarios examined, mean length and age declined rapidly in response to the onset of the fishery and stabilized at considerably lower levels within 100 years. Mean length and age declined more when escapement goals were small and when exploitation 
was higher on small- to medium-sized runs. This suggests that exceeding minimum escapement goals in years of small returns may increase resiliency to selection in subsequent generations.

Several important responses of the modeled population, some expected from theory and others less predictable, were apparent in the results. For example, the reduction in length and age depended on population productivity. Because the base escapement goal $S_{\mathrm{MSY}}$ was independently established for high- and low-productivity simulations and $S_{\text {MSY }}$ occurs at lower escapements for more productive populations, exploitation rates tended to be greater in the high-productivity simulations and led to a stronger response. Regardless of productivity, higher escapement goals were associated with higher run sizes and with smaller changes in length and age. Because improved management precision increased the effectiveness of catching larger, older fish, especially when the population was more productive, there was a tendency for run size and escapement to decline more under these circumstances (results not shown). These results suggest that high productivity itself may not ensure resilience to sustained high exploitation rates. We found that a precisely managed fishery on a productive population tended to increase the selection differential on length and reduce run size and escapement over the long term, a result that highlights the importance of both the size and demographic composition of escapements to maintain resiliency to selective exploitation.

In each of the two productivity scenarios, reductions in mean length and age after 200 years of fishing tended to be affected most strongly by the escapement goal and exploitation rate on smaller runs. Similar patterns were observed for changes in individual fecundity and total egg deposition. The interaction between exploitation rate and escapement level was fundamental in determining the evolutionary response. This result suggests that management based on maintaining escapement above the $S_{\mathrm{MSY}}$ level derived from traditional stock-recruit analyses may help to minimize fishery-induced evolution, although what level of escapement is optimal remains uncertain.

In most of the cases we considered, management intervention had meager success in reversing declines in mean length and age unless multiple changes were implemented simultaneously. As expected, eliminating fishing completely produced the most rapid recoveries in size and age because genetic variation present in both traits permitted 
responses to relaxed selection. A modest reduction in mesh size alone was generally ineffective given the large reduction in length observed, as the smaller-meshed gear continued to target the largest remaining individuals and effectively preclude recovery in the absence of other remedies. Management options to reduce exploitation and mesh size were much more effective in stimulating a recovery when implemented jointly and were most effective when a sufficient number of larger, older fish were still present in the population. The simulations showed an ultimate convergence of final phenotypes between the no fishing and some conservative fishing scenarios, but convergence generally required many generations.

Our findings are qualitatively similar to those of other exploratory studies. In particular, our results show strong similarities to those of Hard [2004], Hard et al. [2009], and Eldridge et al. [2010], who used a deterministic model of phenotypic evolution in Chinook salmon populations to show that size-selective fishing could produce a detectable evolutionary response in size at age within a few decades if both exploitation rate and size selectivity are sufficiently strong. Hard et al. [2009] predicted that the lengths of adults of most ages would decline under selection within 100 years, even if the selection differential is small on fish of older ages, due to the correlated heritabilities of lengths expressed at different ages. A modest but realistic heritability of length $\left(h^{2} \sim 0.3\right)$ appeared to permit some recovery of length at age after cessation of fishing. Thus, given sufficient genetic variability, a population could adapt to fishing selection to reach a higher abundance, but fishery yields were likely to take much longer to respond to management intervention.

Resolving uncertainties regarding the effects of fishery-induced evolution for Chinook salmon will require careful monitoring of long-term trends in exploited populations that differ in features that do not confound fishing effects, or carefully designing fishing "experiments" to quantify these effects (NRC [2005]). It is difficult to identify practical situations where such experiments could be carried out; therefore, we believe it is important for managers to be precautionary about the potential genetic effects of fishing in managing salmon fisheries.

Fisheries that exert substantial mortality can be expected to alter the demography and reproductive potential of populations; this is a 
basic tenet of population biology and fisheries management. We observed such effects under all the fishing scenarios we explored, and our results are consistent with those of others who have argued that any extra mortality exerted by fishing is likely to produce changes in population characteristics as adaptation to fishing occurs (e.g., Policansky [1993a,b]). Size-selective fisheries that disproportionately remove larger, older fish can reduce intrinsic potential more than fisheries that are not selective because of the greater fecundity (and perhaps higher gamete quality and habitat selectivity) of these individuals. Because both size and age are heritable in Chinook salmon, these challenges to population resilience can be compounded over time through evolutionary response to selection on those traits.

If exploited populations are to cope with the ecological and evolutionary pressures posed by fishing, they must retain the adaptive capacity to respond. Fishery-induced evolution might compound the demographic risk posed by overexploitation, and this evolutionary trend could be difficult to reverse (Conover et al. [2009]). As fish adapt to exploitation, they are likely to evolve away from configurations that natural and sexual selection alone would favor. Given sufficient genetic variability and a predictable fishing regime typified by moderate to high exploitation rates, salmon ought to respond to fishing selection by increasing growth rate and reducing the mean age at maturation. Whether such adaptations can improve population viability in the face of continued fishing depends largely on two conditions: genetic variability in size and age is not diminished by selection, and productivity is not eroded by consequent changes in size, age, and fertility of breeding adults. Even if aggressive reduction of fishing mortality is sufficient to permit a population to recover total run size, achieving original age and size distributions is likely to take much longer.

The management of Chinook salmon should encompass all aspects of their ecology, including the potential for fishery-induced adaptation. Our results provide important indications of how Chinook salmon populations might be expected to respond to long-term, selective exploitation of the largest individuals. Reductions in mean length, maturation age, population productivity, and related traits seem highly likely to occur, even though the magnitudes of the declines are currently difficult to predict. Furthermore, recovery after management intervention may be more protracted than the rate of decline. Our findings also 
suggest that socially and economically disruptive management intervention might be required to accomplish population recovery if the oldest and largest fish are extirpated. A modest reduction in mesh size alone is unlikely to be an effective management response in that eventuality. Fisheries management would benefit by adopting a risk-averse perspective and explicitly linking exploitation rates and selectivity of the fishery to the degree of certainty in the condition of the breeding population (Gerrodette et al. [2002]). The adoption of such a precautionary perspective might forestall future decline and increase the potential for Chinook salmon to persist as a viable and diverse resource that can support a fishery as well as adapt successfully to future natural challenges.

Acknowledgments. We thank Danielle Evenson and Toshihide Hamazaki (Alaska Department of Fish and Game, Commercial Fisheries Division, Anchorage Alaska) for providing data on Yukon River Chinook salmon. David Patterson and Michael Bradford (Department of Fisheries and Oceans, Cooperative Resource Management Institute, School of Resource and Environmental Management, Simon Fraser University, Burnaby, British Columbia) provided assistance via discussions of the reproductive behavior and survival of salmon. We thank Lyman McDonald (West Inc., Laramie, Wyoming) for helpful comments and review of the proposed models during model development. David Hankin (Department of Fisheries Biology, Humboldt State University, Arcata, California) and Brian Riddell (Department of Fisheries and Oceans, Pacific Biological Station, Nanaimo, British Columbia) provided insightful technical reviews of a draft agency report that were extremely helpful in improving the contents and presentation of the manuscript. This work was partially funded under award NA16FP2993 from the National Oceanic and Atmospheric Administration, U.S. Department of Commerce, as authorized by the Arctic Yukon Kuskokwim Sustainable Salmon Initiative (www.aykssi.org). The statements, findings, conclusions, and recommendations are those of the authors and do not necessarily reflect the views of the National Oceanic and Atmospheric Administration, the Department of Commerce, the Arctic Yukon Kuskokwim Sustainable Salmon Initiative, or the U. S. Fish and Wildlife Service. Karen Gillis (Arctic Yukon Kuskokwim Sustainable Salmon Initiative and Bering Sea Fishermen's Association, Anchorage, 
Alaska) provided invaluable administrative support throughout the duration of this investigation. The editor and two anonymous reviewers provided valuable suggestions for improving the manuscript.

\section{REFERENCES}

D.G. Ainley and L.K. Blight [2009], Ecological Repercussions of Historical Fish Extraction from the Southern Ocean, Fish Fish. 10, 13-38.

F.W. Allendorf, P.R. England, G. Luikart, P.A. Ritchie, and N. Ryman [2008], Genetic Effects of Harvest on Wild Animal Populations, Trends Ecol. Evol. 23, $327-337$.

F.W. Allendorf, and J.J. Hard [2009], Human-Induced Evolution Caused by Unnatural Selection through Harvest of Wild Animals, Proc. Natl. Acad. Sci. USA 106, 9987-9994.

K.H. Andersen, K.D. Farnsworth, U.H. Thygesen, and J.E. Beyer [2007], The Evolutionary Pressure from Fishing on Size at Maturation of Baltic Cod, Ecol. Model. 204, 246-252.

J. Bales [2008], Salmon Age and Sex Composition and Mean Lengths for the Yukon River Area, 2006, Alaska Department of Fish and Game, Fishery Data Series No. 08-14. Anchorage, Alaska. Available at: http://www.sf.adfg. state.ak.us/FedAidPDFs/fds08-14.pdf. Accessed January 5, 2010.

R. Beaudouin, G. Monod, and V. Ginot [2008], Selecting Parameters for Calibration via Sensitivity Analysis: An Individual-Based Model of Mosquitofish Population Dynamics, Ecol. Model. 218, 29-48.

B. Berejikian, E.P. Tezak, and A.L. LaRae [2000], Female Mate Choice and Spawning Behaviour of Chinook Salmon under Experimental Conditions, J. Fish Biol. 57, 647-661.

B.S. Bigler, D.W. Welch, and J.H. Helle [1996], A Review of Size Trends among North Pacific Salmon (Oncorhynchus spp.), Can. J. Fish. Aquat. Sci. 53, 455-465.

M.J. Bradford [1995], Comparative Review of Pacific Salmon Survival Rates, Can. J. Fish. Aquat. Sci. 52, 1327-1338.

J.F. Bromaghin [2005], A Versatile Net Selectivity Model, with Application to Pacific Salmon and Freshwater Species of the Yukon River, Alaska, Fish. Res. 74, 157-168.

C.J. Brown, A.J. Hobday, P.E. Ziegler, and D.C. Welsford [2008], Darwinian Fisheries Science Needs to Consider Realistic Fishing Pressures over Evolutionary Time Scales, Mar. Ecol. Prog. Ser. 369, 257-266.

L.S. Buklis [1999], A Description of Economic Changes in Commercial Salmon Fisheries in a Region of Mixed Subsistence and Market Economies, Arctic 52, 40-48.

K.P. Burnham and D.R. Anderson [2002], Model Selection and Multimodel Inference: A Practical Information-Theoretic Approach, Springer-Verlag, New York.

S.M. Carlson, E. Edeline, L.A. Vøllestad, T.O. Haugen, I.J. Winfield, J.M. Fletcher, J.B. James, and N.C. Stenseth [2007], Four Decades of Opposing 
Natural and Human-Induced Artificial Selection Acting on Windermere Pike (Esox lucius), Ecol. Lett. 10, 512-521.

S.M. Carlson and T.R. Seamons [2008], A Review of Quantitative Genetic Components of Fitness in Salmonids: Implications for Adaptation to Future Change, Evol. Appl. 1, 222-238.

H.C. Carroll and B.C. McIntosh [2008], Sonar Estimation of Salmon Passage in the Yukon River near Pilot Station, 2006, Alaska Department of Fish and Game, Fishery Data Series No. 08-65. Anchorage, Alaska. Available at: http://www.sf.adfg.state.ak.us/FedAidpdfs/Fds08-65.pdf. Accessed 24 July, 2009.

W.J. Conover [1999], Practical Nonparametric Statistics, 3rd ed., John Wiley \& Sons, New York.

D.O. Conover and S.B. Munch [2002], Sustaining Fisheries Yields over Evolutionary Time Scales, Science 297, 94-96.

D.O. Conover, S.B. Munch, and S.A. Arnott [2009], Reversal of Evolutionary Downsizing Caused by Selective Harvest of Large Fish, Proc. R. Soc. B 276, 2015-2020.

K.R. Criddle [1996], Predicting the Consequences of Alternative Harvest Regulations in a Sequential Fishery, N. Am. J. Fish. Man. 16, 30-40.

E. Edeline, S.M. Carlson, L.C. Stige, I.J. Winfield, J.M. Fletcher, J.B. James, T.O. Haugen, L.A. Vøllestad, and N.C. Stenseth [2007], Trait Changes in a Harvested Population Are Driven by a Dynamic Tug-of-War between Natural and Harvest Selection, Proc. Natl. Acad. Sci. USA 104, 15799-15804.

D.M. Eggers [1993], Robust Harvest Policies for Pacific Salmon Fisheries, in (G. Kruse, D.M. Eggers, R.J. Marasco, C. Pautzke, and T.J. Quinn, eds.), Proceedings of the International Symposium on Management Strategies for Exploited Fish Populations, Alaska Sea Grant College Program Report No. 93-02, University of Alaska, Fairbanks.

W.H. Eldridge, J.J. Hard, and K.A. Naish [2010], Simulating Fishery-Induced Evolution in Chinook Salmon: The Role of Gear, Location and Genetic Correlations Among Traits, Ecol. Appl. 20, 1936-1948.

C.S. Elphick [2008], How You Count Counts: The Importance of Methods Research in Applied Ecology, J. App. Ecol. 45, 313-1320.

M.J. Evenson [2002], Optimal Production of Chinook Salmon from the Chena and Salcha Rivers, Alaska Department of Fish and Game, Fishery Manuscript Series No. 02-01, Anchorage, Alaska. Available at: http://www.sf.adfg.state. ak.us/FedAidPDFs/fms02-01.pdf. Accessed June 2008.

D.S. Falconer and T.F.C. McKay [1996], Introduction to Quantitative Genetics, 4 th ed. Addison Wesley Longman, Essex, UK, 464 p.

FAO (Fisheries and Agriculture Organization) [2004], The State of World Fisheries and Agriculture 2004, Fisheries Department, Food and Agriculture Organization of the United Nations, Rome. Available at: http://www.fao.org/ docrep/007/y5600e/y5600e00.htm. Accessed June 2008.

P.B. Fenberg and K. Roy [2008], Ecological and Evolutionary Consequences of Size-Selective Harvesting: How Much do we Know?, Mol. Ecol. 17, 209-220.

C.J. Foote [1988], Male Mate Choice Dependent on Male Size in Salmon, Behaviour 106, 63-80. 
M. Fukuwaka and K. Morita [2008], Increase in Maturation Size after the Closure of a High Seas Gillnet Fishery on Hatchery-Reared Chum Salmon Oncorhynchus keta, Evol. Appl. 1, 376-387.

T. Gerrodette, P.K. Dayton, S. Macinko, and M.J. Fogarty [2002], Precautionary Management of Marine Fisheries: Moving Beyond Burden of Proof, Bull. Mar. Sci. 70, 657-668.

V. Ginot, S. Gaba, R. Beaudouin, F. Aries, and H. Monod [2006], Combined Use of Local and ANOVA-Based Global Sensitivity Analyses for the Investigation of a Stochastic Dynamic Model: Application to the Case Study of an Individual-Based Model of a Fish Population, Ecol. Model. 193, 479-491.

T.R. Hamon, C.J. Foote, R. Hilborn, and D.E. Rogers [2000], Selection on Morphology of Spawning Wild Sockeye Salmon by a Gill-Net Fishery, Trans. Am. Fish. Soc. 129, 1300-1315.

D.G. Hankin and M.C. Healey [1986], Dependence of Exploitation Rates for Maximum Yield and Stock Collapse on Age and Sex Structure of Chinook Salmon (Oncorhynchus tshawytscha) Stocks, Can. J. Fish. Aquat. Sci. 43, 1746-1759.

D.G. Hankin, J.W. Nicholas, and T.W. Downey [1993], Evidence for Inheritance of Age of Maturity in Chinook Salmon, Oncorhynchus tshawytscha, Can. J. Fish. Aquat. Sci. 50, 347-358.

J.J. Hard [1995], A Quantitative Genetic Perspective on the Conservation of Intraspecific Diversity, Am. Fish. Soc. Symp. 17, 304-326.

J.J. Hard [2004], Evolution of Chinook Salmon Life History under Size-Selective Harvest, in (A. Hendry and S. Stearns, eds.), Evolution Illuminated: Salmon and Their Relatives, Oxford University Press, New York.

J.J. Hard, W.H. Eldridge, and K.A. Naish [2009], Genetic Consequences of SizeSelective Fishing: Implications for Viability of Yukon River Chinook Salmon in the Arctic-Yukon-Kuskokwim Region of Alaska, Am. Fish. Soc. Symp. 70, 759-780.

J.J. Hard, M.R. Gross, M. Heino, R. Hilborn, R.G. Kope, R. Law, and J.D. Reynolds [2008], Evolutionary Consequences of Fishing and their Implications for Salmon, Evol. Appl. 1, 388-408.

M.C. Healey [1986], Optimum Size and Age at Maturity in Pacific Salmon and Effects of Size-Selective Fisheries, in (D.J. Meerburg, ed.) Salmonid Age at Maturity, Canadian Special Publication in Fisheries and Aquatic Sciences 89; Ottawa, Ontario.

M. Heino [1998], Management of Evolving Fish Stocks, Can. J. Fish. Aquat. Sci. 55, 1971-1982.

R. Hilborn [1985], Simplified Calculation of Optimum Spawning Stock Size from Ricker's Stock Recruitment Curve, Can. J. Fish. Aquat. Sci. 42, 1833-1834.

R. Hilborn and C.V. Minte-Vera [2008], Fisheries-Induced Changes in Growth Rates in Marine Fisheries: Are They Significant?, Bull. Mar. Sci. 83, 95-105.

J.A. Hutchings [2000], Collapse and Recovery of Marine Fishes, Nature 406, $882-885$.

J.A. Hutchings and S. Rowe [2008], Consequences of Sexual Selection for Fisheries-Induced Evolution: An Exploratory Analysis, Evol. Appl. 1, 129-136.

K.E. Hyer and C.J. Schleusner [2005], Chinook Salmon Age, Sex, and length Analysis from Selected Escapement Projects on the Yukon River, U.S. Fish and 
Wildlife Service, Alaska Fisheries Technical Report 87, Anchorage, Alaska. Available at: http://alaska.fws.gov/fisheries/fish/Technical_Reports/t_2005_87.pdf. Accessed June 2008.

ICES (International Council for the Exploration of the Sea) [2007], Report of the Working Group on North Atlantic Salmon (WGNAS), 4-13 April 2006, ICES Headquarters. ICES CM 2006/ACFM:23, 254 pp. Available at: http://www.ices.dk/iceswork/wgdetailacfm.asp?wg=WGNAS. Accessed June 2008.

J.R. Jasper and D.F. Evenson [2006], Length-girth, length-weight, and Fecundity of Yukon River Chinook Salmon Oncorhynchus tshawytscha, Alaska Department of Fish and Game, Divisions of Sport Fish and Commercial Fisheries, Fishery Data Series No. 06-70, Anchorage, Alaska. Available at: http://www.sf.adfg.state.ak.us/FedAidPDFs/fds06-70.pdf. Accessed June 2008.

N.L. Johnson, S. Kotz, and N. Balakrishnan [1995], Continuous Univariate Distributions, Vol. 2, 2nd ed. John Wiley \& Sons, New York.

C. Jørgensen, K. Enberg, E.S. Dunlop, R. Arlinghaus, D.S. Boukal, K. Brander, B. Ernande, A. Gårdmark, F. Johnston, S. Matsumura, H. Pardoe, K. Raab, A. Silva, A. Vainikka, U. Dieckmann, M. Heino, and A.D. Rijnsdorp [2007], Managing Evolving Fish Stocks, Science 318, 1247-1248.

JTC (Joint Technical Committee of the Yukon River US/Canada Panel) [2006], Potential Causes of Size Trends in Yukon River Chinook Salmon Populations, Alaska Department of Fish and Game, Division of Commercial Fisheries, Regional Information Report No. 3A06-07, Anchorage, Alaska. Available at: http://www.cf.adfg.state.ak.us/region3/pubs/yukon/06bofjtcchin.pdf. Accessed June 2008.

JTC (Joint Technical Committee of the Yukon River U.S./Canada Panel) [2008], Yukon River Salmon 2007 Season Summary and 2008 Season Outlook, Alaska Department of Fish and Game, Division of Commercial Fisheries, Regional Information Report No. 3A08-01, Anchorage, Alaska. Available at: http://www.sf.adfg.state.ak.us/FedAidPDFs/fds06-70.pdf. Accessed June 2008.

V. Kaitala and W.M. Getz [1995], Population Dynamics and Harvesting of Semelparous Species with Phenotypic and Genetic Variability in Reproductive Age, J. Math. Biol. 33, 521-556.

N. Kendall, J.J. Hard, and T.P. Quinn [2009], Quantifying Six Decades of Fishery Selection for Size and Age at Maturity in Sockeye Salmon, Evol. Appl. 2, 523536 .

S. Kotz, N. Balakrishnan, and N.L. Johnson [2000], Continuous Multivariate Distributions, Volume 1: Models and Applications, 2nd ed., John Wiley \& Sons, New York.

A. Kuparinen, S. Kuikka, and J. Merilä [2009], Estimating Fisheries-Induced Selection: Traditional Gear Selectivity Research Meets Fisheries-Induced Evolution, Evol. Appl. 2, 234-243.

A. Kuparinen and J. Merilä [2007], Detecting and Managing Fisheries-Induced Evolution, Trends Ecol. Evol. 22, 652-659.

P.A. Larkin [1977], An Epitaph for the Concept of Maximum Sustained Yield, Trans. Am. Fish. Soc. 106, 1-11. 
R. Law [1991], On the Quantitative Genetics of Correlated Characters under Directional Selection in Age-Structured Populations, Philo. Trans. R. Soc. London, Series B 331, 213-223.

R. Law [2000], Fishing, Selection, and Phenotypic Evolution, ICES J. Mar. Sci. 57, 659-668.

R. Law [2007], Fisheries-Induced Evolution: Present Status and Future Directions, Mar. Ecol. Prog. Ser. 335, 271-277.

P.S. Levin, E.E. Holmes, K.R. Piner, and C.J. Harvey [2006], Shifts in a Pacific Ocean Fish Assemblage: The Potential Influence of Exploitation, Conserv. Biol. 20, 1181-1190.

J. Martínez-Garmendia [1998], Simulation Analysis of Evolutionary Response of Fish Populations to Size-Selective Harvesting with the Use of An Individual-Based Model, Ecol. Model. 111, 37-60.

M. Metcalf, J. Reid, and M. Cohen [2004], Fortran 95 /2003 Explained, Oxford University Press, New York.

K.A. Naish and J.J. Hard [2008], Bridging the Gap between the Genotype and the Phenotype: Linking Genetic Variation, Selection and Adaptation in Fishes, Fish Fish. 9, 396-422.

NRC (National Research Council) [2005], Developing a Research and Restoration Plan for Arctic-Yukon-Kuskokwim (Western Alaska) Salmon. The National Academies Press, Washington, DC.

A. Olausson and K. Ronningen [1975], Estimation of Genetic Parameters for Threshold Characters, Acta Agric. Scand. 25, 201-208.

D. Policansky [1993a], Fishing as a Cause of Evolution in Fishes, in (T.K. Stokes, J.M. McGlade, and R. Law, eds.), The Exploitation of Evolving Resources, Vol. 99. Springer-Verlag, Berlin.

D. Policansky [1993b], Evolution and Management of Exploited Fish Populations, in (G. Kruse, D.M. Eggers, R.J. Marasco, C. Pautzke, and T.J. Quinn, eds.), Management Strategies for Exploited Fish Populations, University of Alaska Sea Grant, Fairbanks, Alaska.

T.P. Quinn [2005], The Behavior and Ecology of Pacific Salmon \& Trout, Washington University Press, Seattle, Washington.

T.P. Quinn, J.A. Peterson, V. Gallucci, W.K. Hershberger, and E.L. Brannon [2002], Artificial Selection and Environmental Change: Countervailing Factors Affecting the Timing of Spawning by Coho and Chinook Salmon, Tran. Am. Fish. Soc. 131, 591-598.

S. Ratner and R. Lande [2001], Demographic and Evolutionary Responses to Selective Harvesting in Populations with Discrete Generations, Ecology 82, 3093-3104.

RDCT (R Development Core Team) [2007], $R$ : A Language and Environment for Statistical Computing. R Foundation for Statistical Computing, Vienna, Austria. ISBN 3-900051-07-0, Available at: http://www.R-project.org.

D. Réale and D.A. Roff [2001], Estimating Genetic Correlations in Natural Populations in the Absence of Pedigree Information: Accuracy and Precision of the Lynch Method, Evolution 55, 1249-1255. 
W.E. Ricker [1958], Maximum Sustained Yields from Fluctuating Environments and Mixed Stocks, J. Fish. Res. Board Can. 15, 991-1006.

W.E. Ricker [1969], Effects of Size-Selective Mortality and Sampling Bias on Estimates of Growth, Mortality, Production and Yield, J. Fish. Res. Board Can. 261, 479-541.

W.E. Ricker [1975], Computation and Interpretation of Biological Statistics of Fish Populations, Bull. Fish. Res. Bd. Can. 191, Ottawa, Canada.

W.E. Ricker [1981], Changes in the Average Size and Age of Pacific Salmon, Can. J. Fish. Aquat. Sci. 38, 1636-1656.

W.E. Ricker [1995], Trends in the Average Size of Pacific Salmon in Canadian Catches, in (R.J. Beamish, ed.) Climate Change and Northern Fish Populations, Canadian Special Publication in Fisheries and Aquatic Sciences 121, Ottawa, Ontario.

B.E. Riddell [1986], Assessment of Selective Fishing on the Age at Maturity in Atlantic Salmon (Salmo salar): A Genetic Perspective, in (D.J. Meerburg, ed.), Salmonid Age at Maturity, Canadian Special Publication in Fisheries and Aquatic Sciences 89, Ottawa, Ontario.

K. Ronningen [1974], Monte Carlo Simulation of Statistical-Biological Models which Are of Interest in Animal Breeding, Acta Agric. Scand. 24, 135-142.

C. Safina and D.H. Klinger [2008], Collapse of Bluefin Tuna in the Western Atlantic, Conserv. Biol. 22, 243-246.

G.A.F. Seber [1977], Linear Regression Analysis, John Wiley \& Sons, New York.

C. Skaugstad and B. McCracken [1991], Fecundity of Chinook salmon, Tanana River, Alaska, Alaska Department of Fish and Game, Division of Sport Fish, Fishery Data Series No. 91-8, Anchorage, Alaska. Available at: http://www.sf.adfg.state.ak.us/FedAidPDFs/fds91-08.pdf. Accessed June 2008.

D.P. Swain, A.F. Sinclair, and J.M. Hanson [2007], Evolutionary Response to Size-Selective Mortality in an Exploited Fish Population, Proc. R. Soc. Lond. B 274, 1015-1022.

E. Vaughan [1947], Time of Appearance of Pink Salmon Runs in Southeastern Alaska, Copeia 1947, 40-50.

M.R. Walsh, S.B. Munch, S. Chiba, and D.O. Conover [2006], Maladaptive Changes in Multiple Traits Caused by Fishing: Impediments to Population Recovery, Ecol. Lett. 9, 142-148.

C.J. Walters and S.J.D. Martell [2004], Fisheries Ecology and Management, Princeton University Press, Princeton, NJ.

J. Weidner [1972], Upper Yukon River Fishery Investigations, 1971, Alaska Department of Fish and Game, Division of Commercial Fisheries, AYK Region Stock Status Report \#7, Anchorage, Alaska. Available from the authors. 